Research, part of a Special Feature on Designing Transformative spaces for sustainability in social-ecological systems

\title{
Stories in social-ecological knowledge cocreation
}

\author{
$\underline{\text { Diego Galafassi }}^{1}$, Tim M. Daw $^{2}$, Matilda Thyresson $^{3}$, Sergio Rosendo $^{4,5}$, Tomas Chaigneau $^{6}, \underline{\text { Salomão Bandeira }}^{7}, \underline{\text { Lvdiah Munvi }}^{8}$, \\ Ida Gabrielsson ${ }^{3}$ and Katrina Brown ${ }^{9}$
}

\begin{abstract}
Transformations in social-ecological systems to overturn poverty and ecosystem degradation require approaches to knowledge synthesis that are inclusive and open to creative innovation. We draw on interviews with participants and in-depth process observation of an iterative knowledge cocreation process in Kenya and Mozambique that brought together scientists, community representatives, government representatives, and practitioners who had expertise or experience in poverty and/or coastal natural resource use and management. We analyze the communicative spaces opened by techniques of system diagrams and future scenarios, and provide a rich account of the emergent process of developing a "shared conceptual repertoire" as a basis for effective communication and knowledge synthesis. Our results highlight the difficulties of challenging dominant narratives and the creative potential that exists in reflecting on their underpinning assumptions. In our analysis, stories and lived experiences emerged as key means shaping the construction of shared concepts and ideas. We conclude by outlining the implications of designing knowledge cocreation processes that support the task of devising systemic interventions that are robust for a range of future scenarios. This includes embracing the role of stories in generating shared meanings and opening up spaces for exploration of knowledge assumptions that are embedded in intervention narratives.
\end{abstract}

Key Words: action research; coproduction; learning; Kenya; Mozambique; participatory; transdisciplinarity; transformations

\section{INTRODUCTION}

The interconnected challenges of poverty alleviation and ecosystem sustainability span multiple scales, and arguably, their roots lie in the ways in which societies understand the world and their relations to natural systems (Folke et al. 2011). To address these root causes, transformations have increasingly been recognized as necessary for sustainability (Olsson et al. 2014, Pelling et al. 2014, Lotz-Sisitka et al. 2016). Transformations are understood as fundamental changes in and across various domains spanning from individuals' mindsets, attitudes, and beliefs to social norms and practices, to institutions and political systems (Brown et al. 2013, O'Brien and Sygna 2013). A socialecological approach emphasizes how these fundamental transformations also lead to changes in natural capital through the reconfiguration of social-ecological relations (Olsson et al. 2014).

Transformations to sustainability require the mobilization of actors across scales and domains in collaborative efforts, which is key to galvanizing new system trajectories (Huitema and Meijerink 2010, Olsson et al. 2014). In these networks, actors can develop shared narratives about system identity, form alliances that may challenge existing power configurations, and connect resources for strategic interventions (Westley et al. 2013). How these shared understandings and ideas for interventions emerge in collaborative networks is still an area of research in transformations studies (Westley et al. 2013, Moore et al. 2015).

At the same time, processes where knowledge is collaboratively developed among practitioners and scientists have been repeatedly proposed as a strategy for integrating various perspectives, values, and knowledge systems on the complex relations between nature and society (Tàbara and Chabay 2013, Tengö et al. 2014). These processes have been studied under a variety of rubrics, including Mode- 2 science, transdisciplinarity, knowledge coproduction, and codesign (Flyvbjerg and Sampson 2009, Mauser et al. 2013, Moser 2016). Despite expanding research on these processes, their contribution to learning and development of capacities that may lead to transformations is less understood (Fazey et al. 2017). We refer to "knowledge cocreation" as a process where a group of actors (including scientists) engage in developing shared understandings and novel ideas of how to intervene in social-ecological systems, in this case, through facilitated workshops.

Techniques derived from a systems perspective, like system diagrams (also referred as cognitive mapping) and scenario planning, have been taken up within social-ecological systems research to support knowledge cocreation (Peterson et al. 2003, Jetter and Kok 2014, Oteros-Rozas et al. 2015). These techniques have been found to contribute to the construction of common understanding among participants, and by fostering learning about plausible futures, they may inform policy and enrich environmental management (Carpenter et al. 2006, Rogers 2013, Oteros-Rozas et al. 2015)

Processes of knowledge cocreation usually convene a diverse group of people in a communicative process that unfolds in a symbolically rich social and cultural context, often difficult to describe and analyze (Wiek et al. 2014). In these spaces, participants express themselves and seek to understand others through a range of cultural tools, including metaphors, images,

\footnotetext{
${ }^{1}$ Stockholm Resilience Centre, Stockholm University, Sweden, ${ }^{2}$ Stockholm Resilience Centre, Stockholm University, Stockholm, Sweden, ${ }^{3}$ Stockholm Resilience Centre, Stockholm University, ${ }^{4}$ Interdisciplinary Centre of Social Sciences, Faculdade de Ciências Sociais e Humanas, Universidade Nova de Lisboa, Portugal, ${ }^{5}$ School of International Development, University of East Anglia, Norwich, UK, ${ }^{6}$ Environment and Sustainability Institute, University of Exeter, Penryn, Cornwall, UK, TR10 9FE, ${ }^{7}$ Department of Biological Sciences, Universidade Eduardo Mondlane, PO Box 257, Maputo, Mozambique, ${ }^{8}$ Independent Natural Resource Governance Consultant, P.O. Box 59782 (00200), Nairobi, Kenya., ${ }^{9}$ College of Life and Environmental Sciences, University of Exeter, Exeter, Devon, UK
} 
stories, and narratives. Although "building a common language" is often cited as a first step toward the development of collective ways of thinking about the dynamics of social-ecological systems, there are still research gaps about how multiple meanings are expressed, contested, and eventually become shared (Daré et al. 2013, Fazey et al. 2014). Newell (2012) looks at this in the context of interdisciplinary communication bringing attention to the importance of metaphors and the relation they establish between lived experiences and abstract concepts. His view highlights how language and cognition are deeply intertwined with bodily experiences in the world (Lakoff and Johnson 1999). Further, questions remain in understanding how "shared conceptual repertoires" (Newell 2012) may support participants in challenging existing narratives and their assumptions in the search for novel ways of framing and ideas for interventions.

Although the terms "stories" and "narratives" are often used interchangeably in literature, we understand stories as specific and particular accounts of certain events and lived experiences, often at a low level of abstraction. We see narratives (i.e., socialecological narratives or intervention narratives) as more general and abstract expressions of how one sees causal linkages between certain aspects of a particular system (Lynam and Brown 2012). For example, a narrative could be that "healthy ecosystems are important to support communities' well-being," whereas a story would be an account of how the community is experiencing resource fluctuation. These social-ecological narratives can be composed of multiple stories, they have an internal logic as they frame problems and solutions in particular ways, and they can line up with existing power arrangements (Leach et al. 2010). For this reason, social-ecological narratives can be sources of both lock in, when particular framings suppress novelty, and renewal as narratives legitimate new ideas and practices (Leach et al. 2010, Lynam and Brown 2012). Challenging dominant socialecological narratives is often cited as a key trigger of transformation toward sustainability (Moore et al. 2014).

We analyze an iterative knowledge cocreation process among practitioners (including scientists) in Kenya and Mozambique in the context of poverty alleviation and ecosystems sustainability. We focus our analysis on the communicative aspects of the process as participants engage in conversations with the support of techniques of system diagrams and scenario planning. Our goal is to gain insights on how workshop participants developed shared meanings and how shared understandings may lead to novel thinking, questioning, and reframing of social-ecological narratives of interventions presumably aimed at addressing the interconnected challenges of poverty alleviation and ecosystem degradation.

\section{CASES AND RESEARCH APPROACH}

\section{Context}

The cocreation process was focused on the interactions of poverty and coastal ecosystems in the Mombasa and Kwale district in southern Kenyan and in Cabo Delgado Province of northern Mozambique. The workshops were conducted as part of a large transdisciplinary project (Sustainable Poverty Alleviation from Coastal Ecosystem Services http://www.espa-spaces.org), which also collected empirical data on poverty, well-being, use of ecosystem services, and status of coral reefs and mangroves at four different sites in each of the two countries. The study area in both countries is represented by high poverty rates $(57 \%$ in Kenyan coastal district living under US $\$ 1.25$ a day; $50 \%$ in Cabo Delgado, Mozambique living under US\$2 a day [MEF 2016]) and coastal ecosystems ranging from heavily to moderately exploited in urban areas and remote rural areas, respectively. In terms of governance, both countries are currently undergoing decentralization. In Kenya, the new constitution (2010) devolves power and resources from central to county scales. Similarly, in Mozambique, national policies and legal frameworks encourage decentralized management of natural resources, including mechanisms for community engagement in management of fisheries and related resources (Järnberg 2016, Rosendo 2016).

\section{Case description}

The studied cocreation processes were composed of a two- and a three-day workshop organized by SPACES project scientists in each country in 2015. The workshops were designed and facilitated by a team of SPACES scientific team members from Sweden, the UK, Mozambique, and Kenya who engaged in joint training in workshop facilitation of system mapping and narrative scenarios and developed and rehearsed the workshop structure together. The encounters had 23 (Kenya) and 25 (Mozambique) participants who represented government agencies, NGOs, and universities, as well as representatives from community groups that had experience with and knowledge of poverty alleviation and sustainable resource management. The stated objective of the process was to 'improve participants' and scientists' understanding of poverty alleviation in this coastal social and ecological system in terms of feedback dynamics, trade-offs, and opportunities for sustainable poverty alleviation."

Despite the conceptual focus of the SPACES project on ecosystem services, we did not specifically frame the workshops around the term, instead opting to explore poverty and environmental change on the coast more broadly. We felt that "ecosystem services" would require unnecessary conceptual explanation and clarification, and may have limited the scope of discussions and excluded key aspects of change, such as governance and large-scale infrastructural development projects.

The first workshop focused on mapping out causal relationships between ecological processes and the well-being of coastal dwellers, and the nature and drivers of change and possible future scenarios. The second meeting involved discussions on findings regarding well-being and ecosystem condition from SPACES empirical research, analysis of potential interventions by using the narrative scenarios generated in the first workshop, exploration of "seeds" for possible future change, and synthesis of key policy messages. Future story lines, illustrations, collages, and role-play were used to support participants' discussions on the effects that particular interventions would have on poverty and ecosystems along the coast. We analyze the communication among participants as they engaged with the various techniques used. A summary of key techniques in the process follows, and detailed descriptions are provided in Appendix 1 (SPACES 2017).

\section{System diagrams}

This exercise followed the Fuzzy Cognitive Maps methodology (van Vliet et al. 2010) in four breakout groups (3-6 people) organized roughly by sector (e.g., community representatives and government officers each in one group). The clustering of 
Table 1. Methodologies and data used to study the cocreation process.

\begin{tabular}{|c|c|c|c|}
\hline Research activity & Target group & Scientific method & Outcomes \\
\hline Preinterviews & Workshop participants & Structured interviews & $\begin{array}{l}\text { Participants' views on current challenges and } \\
\text { solutions }\end{array}$ \\
\hline Preworkshop survey & Workshop participants & Survey & $\begin{array}{l}\text { Key challenges and solutions, and workshop } \\
\text { expectations }\end{array}$ \\
\hline Workshop 1 monitoring & $\begin{array}{l}\text { Workshop participants and } \\
\text { facilitators }\end{array}$ & $\begin{array}{l}\text { System diagrams, scenarios, } \\
\text { process observation, debrief } \\
\text { interviews }\end{array}$ & $\begin{array}{l}\text { Notes of content and interactions during } \\
\text { each group session } \\
\text { Session debrief with facilitator and } \\
\text { notetaker } \\
42 \text { hours of audio recording }\end{array}$ \\
\hline Postworkshop survey & Workshop participants & Survey & $\begin{array}{l}\text { Key insights and how the workshop was } \\
\text { experienced; analysis of network structure } \\
\text { among the participants before the workshop }\end{array}$ \\
\hline Video interviews & Participants and facilitators & Video interview & $\begin{array}{l}\text { Key challenges and solutions, and workshop } \\
\text { experience }\end{array}$ \\
\hline Preworkshop survey & Workshop participants & Survey & $\begin{array}{l}\text { Use of learning from previous workshop, } \\
\text { expectations }\end{array}$ \\
\hline Workshop 2 monitoring & $\begin{array}{l}\text { Workshop participants and } \\
\text { facilitators }\end{array}$ & $\begin{array}{l}\text { Scenarios, dialogue, seeds, } \\
\text { process observation, debrief } \\
\text { interviews }\end{array}$ & $\begin{array}{l}\text { Notes of content and interactions during } \\
\text { each group session } \\
\text { Session debrief observations } \\
54 \text { hours of audio recording }\end{array}$ \\
\hline Postworkshop interview & Workshop participants & Structured interviews & $\begin{array}{l}\text { Key insights and how the workshop was } \\
\text { experienced }\end{array}$ \\
\hline
\end{tabular}

participants by sectors for this exercise was aimed at composing a range of different participants' perspectives. All subsequent breakout groupings aimed to maximize within-group diversity to facilitate exchange and learning. Participants were asked to write on sticky notes the factors that affected well-being of coastal people. These were then clustered into approximately a dozen concepts as the basis of the system diagram. Participants then identified and drew causal connections between the concepts, signalled by arrows and plus and minus signs that indicated the direction and strength of each causal effect.

\section{Narrative scenarios}

The narrative scenarios exercise followed the conventional process applied in social-ecological systems research (Kok and Van Delden 2004, van Vliet et al. 2010). After identifying two key drivers of change, participants proceeded to create four story lines of the future, each featuring a combination of enhanced or decreased intensity of these two drivers; e.g., what would the coastal social-ecological system be like if the key driver " $A$ " would increase and key driver "B" would decrease? These story lines of plausible futures were then fleshed out before the second workshop based on workshop materials and participants' feedback. These scenarios were used to "road test" a selection of interventions that were suggested and voted as most interesting to explore.

In order to further stimulate reflections about the future, another approach for future thinking was applied. The technique takes inspiration from the approach of the project Seeds of a Good Anthropocene (Bennett et al. 2016). In this simplified version of the approach (see Appendix 1 for further details), participants were introduced to the notion of the Anthropocene (Steffen et al. 2015) and to the three-horizons framework (Sharpe et al. 2016). Then participants were asked to describe a single "seed" (a project, an idea, or an approach) that already exists and that if brought to scale or in combination with other "seeds" could give rise to a fundamentally new positive trajectory for the coastal socialecological system. After each participant described a seed, groups were asked to develop a story line of the future by combining the seeds of all participants of the group. Role-play was used by groups to share their story lines with others.

\section{Study methodology}

A range of methods was used to study the knowledge cocreation process (Table 1). The first author analyzed the process and was responsible for the design of the study methods (including interview guidelines and observation protocols), while coauthors were involved in designing and facilitating the knowledge cocreation process. Because of our interest in the development of shared meanings and narratives, we based our analysis not on internal cognitive representations of individuals or on their attributes (who says what), but rather our main focus was on the interactions, cnversations, and structures (techniques) in which these interactions unfolded.

\section{Data collection}

During workshops, six observers took notes on plenary and breakout sessions, using standardized forms to collect both content of discussions and impressions of how discussions evolved in each group; for instance, whether there were conflicts, or if specific participants were dominant, motivated, or disengaged. At the end of each session, a debrief interview with each observer was conducted by the first author. This provided an immediate synthesis of the session and particularly important moments during a given session. Observations were complemented by 96 hours of audio recordings to allow followup analysis and detailed transcriptions of specific moments.

Interviews with participants were conducted before and after the first workshop to map participants' framings of main challenges and opportunities within the coastal system. Each workshop was 
preceded and followed by surveys that gathered information about changes in perspectives on key issues and solutions, and about participants' key learning after the workshop. The first author was introduced to participants as an "independent observer," and conducted participant observation in all meetings by sitting in group and plenary conversations and talking to participants and facilitators during free moments (Denzin and Lincoln 2011). He kept a journal with impressions and preliminary assessments that were revisited during data analysis.

\section{Data analysis}

We implemented a hybrid deductive-inductive approach (Patton 2014), drawing themes around shared meaning and narratives from literature (based on Newell [2012]) and used these to analyze audio recordings and observations. Our results are a combination of patterns in communication and "critical incidents" (Krueger and Casey 2014) that illuminate important dynamics in the emergence of shared meaning and narratives. First, two authors identified, via observation notes and session debrief interviews, important moments and passages related to the overarching questions of shared meaning-making and narratives. The first author listened to audio recordings of these segments and used Atlas.Ti audio capabilities to perform an abridged transcript and coding of portions of the discussions that were relevant to themes. Further, with the same approach, he selected, listened to, and coded a random sample of approximately 10 minutes of audio recordings of each group session that covered different stages of each exercise (total 500 minutes) to map how concepts emerged and map narratives defined through conversations. He wrote short analytical descriptions after listening to each session segment, and these were discussed with the coauthors. We compared how techniques of system diagrams and narrative scenarios influenced and structured conversations. We used the same approach to the analysis of key plenary sessions (total 180 minutes), attending to how concepts from breakout groups resonated in the larger setting.

Interviews were analyzed inductively to generate a list of key "intervention narratives" (sets of problems and associated solutions) that were used by participants in response to a set of questions related to the key challenges and solutions for dealing with poverty and ecosystem degradation. These intervention narratives were compared to preworkshop and postworkshop surveys that also contained similar questions about challenges and solutions. While analyzing audio samples and plenary sessions, we also paid attention to how these narratives were expressed, reinforced, or reframed in interaction with others.

\section{Ethics}

Invited participants were provided, in advance, with a letter that explained the aims and design of the workshops, and with the opportunity of consent. Upon arrival, facilitators emphasized the importance of having open and respectful discussions, and asked everyone to keep information anonymous. Participants' interviews were also conducted with informed consent and anonymity.

\section{RESULTS AND DISCUSSION}

In this section, we reveal some of the key dynamics observed in the creation of shared meaning and in how participants used shared understandings to question and reshape social-ecological narratives. First, we look at how participants came to develop a shared concept, then we explore the ways in which different metaphors led to different understandings and how these understandings fostered insights into the dynamics of the socialecological system. Finally, we turn to the challenge of questioning and reshaping social-ecological narratives.

\section{Developing a shared conceptual repertoire}

"In the beginning it was difficult for people to start with concepts, they wanted to tell a story and to have a concrete issue," reflected one of the facilitators after a session involving community representatives in Mozambique in which participants were developing a system diagram of how well-being of coastal dwellers was linked to changes in coastal ecosystems (see Appendix 1 for detailed process design and images of outcomes). A shared understanding implies that participants are able to draw the same meaning out of abstract concepts used. Concepts are formed by metaphorical associations between a "source domain" of common experience and a "target domain" of more abstract understanding (Fauconnier and Turner 2008). For example, a participant during the first workshop in Mozambique, who explained the concept of "support," said:

The community seeks support, and there are many types
of support: material, educational, technical. If we
prohibitmosquitonets, thosemothers wantmoney to send
their kids to school, for health...there is a need for
support. Then, what does support mean, if we see
someone carrying something heavy on her head, we need
to help carrying. (Mozambique workshop, systems
diagram exercise)

The target domain in this case is providing material support to communities. Here, the source domain of the metaphorical association is made concrete by the participant by sharing the image of helping someone carrying something heavy.

Our analysis of participants' interactions revealed that a common route used for creating shared concepts was by telling stories. Stories helped participants pierce into each other's lived experiences and perspectives. Fig. 1A illustrates a common pattern we found as we investigated the dynamic processes of how groups come to develop a shared concept in workshops in Kenya and Mozambique. In various instances when an abstract concept, for example, "well-being,"was suggested, participants would offer stories about their own community or area of work in the attempt to "unpack" and ground the concept in their lived experiences.

We also observed that the systems diagram technique, as implemented in this workshop, favored abstract conversations by asking participants to list key factors that influence the system rather than allowing groups to build concepts from the ground up.
With the management of "resources," we are influencing "climate change" [...] We need to connect resources negatively with climate change because if the forest is large it will have carbon sequestration. So the more resources, less climate change. (Kenya workshop, participant proposing casual links between resources and climate change in the system diagram exercise)

By suggesting the negative relationship "more resources, less climate change," it is clear that the participant is thinking of 
Fig. 1. Two illustrative renderings of workshop situations. (A) The facilitator asks about the concept of "well-being," and participants "unpack" it by drawing on lived experiences and telling stories about the villages of Maringanha and the city of Pemba in northern Mozambique. The correspondence between experiences supports the creation of a shared concept. (B) The concept of "security" as imagined differently by two participants in Kenya promotes radically different narratives about the system: "high security as presence of security services" and "security as peace."

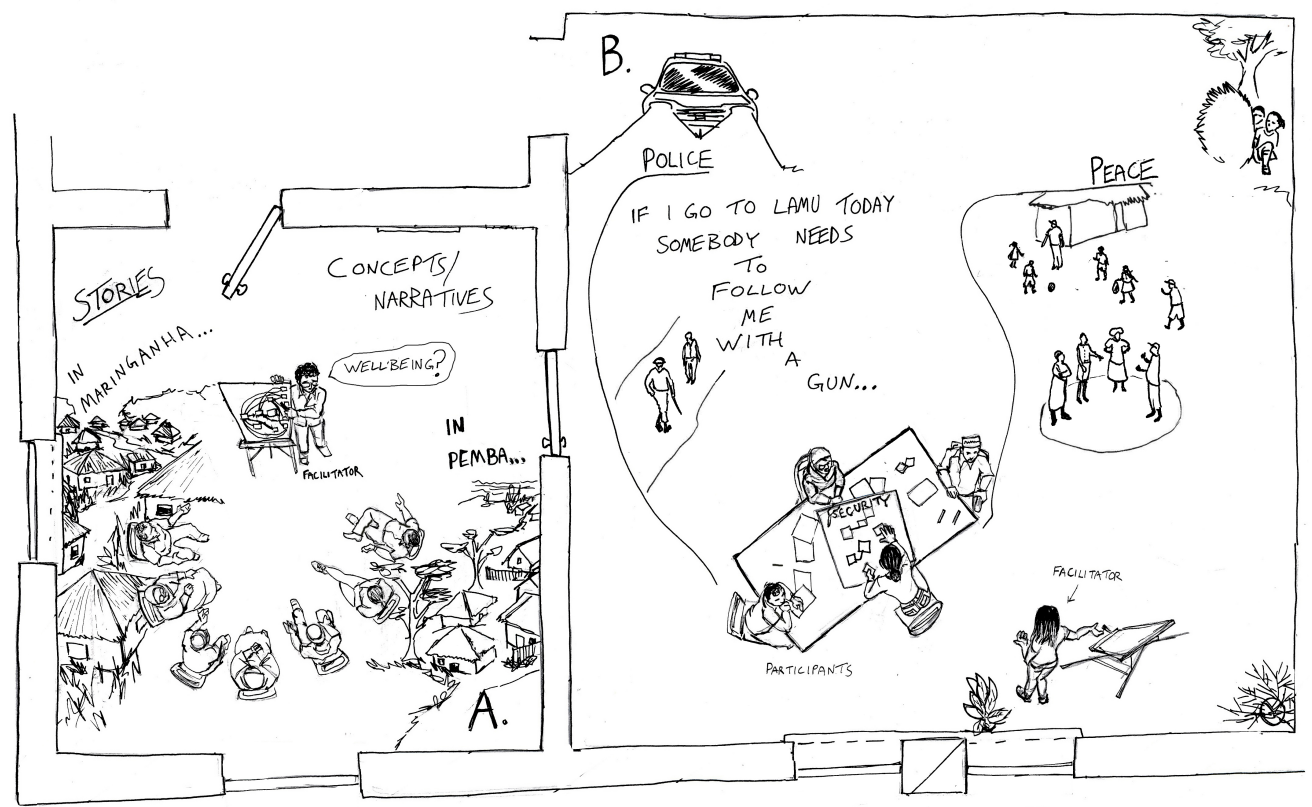

particular kinds of resources and not others, such as fossil fuels (which would actually increase climate change), or as another participant pointed out, "if we have a forest ok. But what if we talk about cows?" This illustrates that even when using abstract terms, participants had in mind specific instances of these concepts.

This issue is particularly important in regard to central terms and concepts used in such cocreation spaces. Even though facilitators were briefed to question participants on meanings of important concepts, and a "glossary" was built by each group to explicitly record the agreed meanings of each concept, in practice, most discussions during the systems diagram exercise session remained at an abstract level, where concepts were suggested without detailed explanations of what they meant to a participant or reference to how these concepts related to experience. There are two main issues with this. First, the agreement at this conceptual level - e.g., "more resources, less climate change" - might be masking a disagreement at a more concrete level-i.e., that the production/use of different kinds of resources might also increase climate change. The second is that abstract discussions without "unpacking" concepts allows personal narratives to get reinforced and not questioned. We return to this implication on narratives in the section Transformative ideas.

This issue is not so accentuated when conversations happen between people who inhabit the same culture and have shared experiences because over time they develop a shared conceptual repertoire, which is then used to make sense and to talk about their reality (Lakoff and Johnson 1999, Fazey et al. 2005). Within a common context, people can communicate effectively using abstract terms that are specific to that context. However, within a diverse knowledge cocreation process, one can expect less overlap between the conceptual repertoires of participants.

As expected, we observed that participants working on a similar area or topic tended to hold concrete experiences as tacit and talked to one another at a more abstract level. This might also explain why some groups found the activity of system diagram easier than others. Developing a shared conceptual repertoire among people from varying contexts would thus require a process through which the group progressively builds a more nuanced understanding of key terms. However, the system diagram technique, with its focus on finding connections between concepts, seems to reverse this process and start from abstract terms. In this, the basic metaphorical associations between concepts and lived experience tended not to be explored.

This led participants from the same group to explain the system diagrams in different ways, suggesting that rather than creating a shared common understanding of the system, the diagrams allowed for multiple interpretations to exist in parallel, arguably reducing the ability of the group to explore the dynamics of the system jointly.

\section{Diverging metaphors, diverging narratives}

Participants engage in a cocreation process with their own views about what constitutes a problem and how to address it (Leach 
Table 2. Policy interventions in each country identified in participant interviews before the workshop and those selected at the end of the second workshop.

\begin{tabular}{lll}
\hline \hline & Interviews before workshops & At the end of workshops \\
\hline Kenya & Sustainable development policies for the coastal zone & Implementation of conservation areas \\
& $\begin{array}{l}\text { Devolution of power to communities and community- } \\
\text { based management of resources }\end{array}$ & Implementation of participatory forest management plans \\
& Education & Onsure ban of illegal gears, and empower community institutions \\
& Improve security levels & Create a gear exchange program \\
& Sensitization and empowerment of communities & Sensitization and training of fisherfolk to adopt better fishing practices \\
& Improved resource management and monitoring & Development of monitoring system and coordination across \\
& Strengthening community participation and local & governance actors \\
& institutions & Encourage communities not to use corals for the production of lime \\
& Develop comprehensive approach where development & Restore mangroves \\
& and community well-being are not in conflict & Empower women to move away from fishing toward other forms of \\
& Enforcement of existing regulations & income generation \\
& Invest in infrastructure & \\
& Financial support &
\end{tabular}

et al. 2010). These framings and understandings are shaped by one's experiences. For example, our interviews with participants in Kenya before the first workshop revealed that the issue of "security" was perceived as a key challenge at the coast in relation to poverty alleviation. According to the interviews, security has wide ranging effects on local livelihoods (mediated by tourism and local security issues) and hence in the way in which socialecological systems evolve. The notion of security, however, was spoken about in different ways. Fig. 1B illustrates a moment in which participants in Kenya were engaged in the creation of story lines for plausible futures in which security is high. The conversation illustrates the encounter of two different metaphors that allow for different imaginations of the future.

Participant 1: 'I'm looking at 'increased security' as increased boots and security forces on the ground, what is the impact in 40 years time?"

Participant 2: "Security does not mean to have a lot of police, it means peace, if you have peace there is no need to have many police, so we have to focus on peace. Police for what?"

Participant 3: "In a Kenyan context, a person only feels safe if he sees a soldier."

Participant 1: "If I go to Lamu today, somebody needs to follow me with a gun."

Participant 2: "Can you remember 10-20 years back? When I was young, once I saw a police passing we used to hide, because we thought they were going to attack. We didn't see as having many police as being safe, no. In the future there will be no police on the road carrying guns...but we will be safe. That means an improvement from now."

Participant 1: "I'm not saying yes or no... [...] in this scenario we are assuming that security is getting better."

Participant 2: "So there is no police on the road, all will be ok!"

Participant 3: "...and things will be ok... Yes, this is an assumption, in 2045 security will be high...yes. “

This is a clear example of where two diverging views of an abstract concept (i.e., security) generated strikingly different narratives of the system. Each participant was drawing their understanding of the concept of "security" from the memory of a lived experience (of requiring security to travel to Lamu, and of memories of youth). As they had the chance to share those stories, we can observe the assumptions (i.e., experiences, images, feelings) that were underpinning the way they thought about the concept of security. The participants, likely because they shared and listened to each other's stories, were able to move toward a shared understanding of the concept, arguably landing on the more encompassing one (peace) rather than the more constraining one (armed police).

However, not all group discussions that were analyzed exhibited such clear and productive articulations of assumptions. We observed a large number of concepts that were not thoroughly discussed, which may have impacted the development of shared, systemic understanding emerging from the discussions. One of the key contributors to this was time available and how the techniques used were driven toward the generation of a specific outcome (system diagram or scenario story line), while the dialogue time that may be required to articulate meanings was constrained.

\section{"Getting a sense" for the system}

So far, we have focused on the construction of a shared conceptual repertoire. Rather than an end in itself, a conceptual repertoire provides a means through which a group can think dynamically and holistically together (coconstruct a model, formal or mental) about how a system behaves and how it would respond to an intervention. A series of exercises invited breakout groups to evaluate how specific interventions would play out in each of the future scenarios.

For example, in the following passage, one group, while exploring a future scenario, grapples with a certain degree of depth, the complex effects of climate change on health and how governance responses could mitigate negative effects (Kenyan workshop, scenarios exercise).

Participant 1: "Climate change will mean increased issues with health."

Participant 2: "It relates more to the density of populations. For instance, if there is an event in which we were not properly ready for, we can have a problem with sanitation (Participant 1: "Yes!"). 
When we have good governance, it means that we will see this and have foresight. We can send health technicians to give lectures, we can create information in relation to use of water, etc."

Participant 1: "So we can prevent health issues through awareness raising."

In contrast to the nuanced exploration of coastal change, other groups exhibited a more rudimentary exploration of system interventions. For example:

This scenario is high security, high community acceptance, so it [the intervention] will definitely work here. Everything is high, so it's going to work. That's Europe, everything works. So Marine Parks can work. (Kenyan workshop, scenarios exercise discussing a scenario of high security and community acceptance)

This would work, because there will be high education, there will be conditions, all the institutions involved will work together because of high governance. (Mozambique workshop, interventions exercise)

This "binary approach" to imagine change ("it will work" or "will not work") was found in several instances across a range of conversations during interventions exercises. There might be several reasons for these disparities between groups, including fatigue and lack of specific expertise. Another factor might have been, along the lines of the point we made in relation to system diagrams, that the groups in these last two quotes leaned toward abstract concepts like "community acceptance" or "education" without exploring their contextual meanings.

\section{Transformative ideas}

The anticipated contribution of knowledge cocreation to transformations is that as a diverse group of participants share a framing about a certain issue, they become more likely to develop shared and innovative ideas for interventions (Wiek et al. 2012, Moore et al. 2014). Although interventions selected at the end of the workshop were more specific, they were generally similar to those identified in interviews with participants before the workshop, which suggests that the process had limited impact on the generation of novel ideas (Table 2).

In Mozambique, the interventions participants selected at the end of the final workshop reflected a particular framing of the coastal challenges being overexploited due to unsustainable practices of natural resource utilization - "overexploitation"-by communities. Solutions reflected a somewhat top-down view of interventions, which perhaps reflected the composition of workshop participants in which community representatives were present but as a minority. Generally, participants from Mozambique thought, in the workshop exit interview, that interventions selected "reflected the biggest ideas and concerns of the different perceptions in the room"; however, one community representative responded (in line with responses from two others) that she "would like to test more interventions to improve the discussions and share more visions." In the Kenyan exit survey, participants gave the lowest satisfaction scores for the interventions and policy recommendations activities. The main negative factor pointed out by many was "lack of time," which was felt to limit the ability of participants "to share their points and to exhaust the most important ideas" (Workshop 2 exit survey).
The final lists of interventions both in Kenya and Mozambique arguably did not reflect a major breakthrough from narratives that commonly circulate in development and sustainability discourses in the regions. Issues of power, authority, and legitimacy are key in influencing the emergence of novel ideas (Barnaud and Van Paassen 2013). Although much effort was put into process design to mitigate these effects (by small breakouts and iterative sessions), power dynamics are to a certain extent inevitable. Further to this, three key insights from our observations of the communication patterns may illuminate constraints and possibilities for innovative thinking.

\section{Breaking away from dominant narratives}

Each participant carries an understanding developed in a particular context of practice (Wenger 2013). Through practice and experience, participants come to develop their own narratives and metaphorical associations that connect lived experiences to more abstract knowledge claims. Abstract terms such as "education" or "security" can hold different meanings for a community representative and a government official. Because of these different meanings, narratives using these concepts can lead to quite different imaginations of strategies to address them. For instance, "education is essential to stop destruction of the environment along the coast." In Kenya, this claim was expressed repeatedly in preworkshop interviews with participants. It holds a range of tacit assumptions, such as what "destruction" is, and what "education" is and for whom. It also assumes that a solution for the coastal challenges are to be found in educating coastal dwellers into particular forms of behavior rather than focusing on structural reform (infrastructure, political, social, economic). Therefore, there can be a creative potential in creating spaces where assumptions can be critically explored by participants (Kegan and Lahey 2009). One may speculate that if the notion of education had been unpacked, participants were more likely to realize that education refers to a range of different concrete actions and programs, and that perhaps some of those are in fact limited in "stopping destruction of the environment," and need to be complemented by other structural solutions.

We found a very limited number of instances of cases in which knowledge assumptions were discussed. This might have been because some of the techniques used favored a higher level of abstraction in conversations, which hindered the exploration of underlying assumptions.

\section{Inquiry into assumptions requires time and focus}

Discovering underlying assumptions and deeper causes of challenges requires time, attention, and dedication to the dialogue. The very process of building a conceptual repertoire by sharing experiences seems to be a way through which groups come across assumptions and are able to reimagine new ones. However, when groups are faced with a time-limited task, be it creating a picture, a system diagram, or a story line depicting changes in a system, the focus on these artifacts can cause the group to glide over deeper conversations. The pressure exerted on a group to create particular artifacts may not allow for an exploration of the deeper causes of issues.

Other similar processes of knowledge cocreation experiences have demonstrated the possibilities of exploring assumptions through participatory modeling and scenarios (Étienne 2011, Galafassi et al. 2017). For instance, Galafassi et al. (2017) showed how the 
participatory coconstruction of the concept of trade-offs fostered a reflection on narratives and management goals of the socialecological system. A key difference is that those examples had a narrower focus of inquiry than the open theme explored in our case ("poverty alleviation and ecosystem health"). There seems to be a trade-off between designing knowledge cocreation with a wide theme as explored in our case and a process with more targeted focus on certain dynamics of the social-ecological system. Although the former might be more open to a variety of discussion and entry points and hence linked to various groups' preoccupations, the latter, narrower focus may allow for a deeper exploration of assumptions and narratives around a particular issue.

\section{Imaginative capacity}

Most of the intervention ideas mentioned during narrative scenario exercises did not represent fundamental changes from current systems. Thinking radically outside of the current system was rare.

\section{There will be less investment in that community. The community cannot bring in development. All forms of support, including funding and technical expertise, comes from external agencies, so if the community is not willing to accept ideas, then development is low. (Kenyan workshop, story line development in scenario of low community acceptance and low security)}

This narrative of "funding depends on external donors" was expressed in two groups during the same exercise. In both cases, the narrative was not questioned, and the groups did not imagine a new assumption; for example, that development may be internally driven.

Similarly, when discussing connections between seed projects, one group imagined the following story line:

\begin{abstract}
So here we started with damaged corals, then here we have rehabilitation, then we go to the training center, it is a resource center where locals are given life skills... and if we have such places where they are free and no cost, the locals whether they are going to school or not they will still be educated how to preserve and take care of the marine ecosystem. (Kenyan workshop, story line development based on seeds)
\end{abstract}

There seems to be an underlying assumption here that lack of education leads to destruction of ecosystems, and the solution is to educate (formally or informally) coastal dwellers. In fact, this narrative of "lack of education as a key driver of ecosystem degradation" was already identified in the preworkshop interviews. This narrative was not questioned within this session, which possibly missed the opportunity for new understandings of drivers of ecosystem destruction or possible solutions. During the "seed technique" exercises, three of four groups proposed an "education center." One group, however, did create a more innovative interpretation of educational centers that "should not have lessons and people would be learning by watching others and developing a stronger sense of solidarity and community."

The overall pattern however was that once "boxes" (in the systems diagram technique) or "seeds" (in the simplified seeds technique) or "drivers" (in the scenarios technique) were put up, it was relatively easy for participants to create a narrative that connected them. However, it was significantly more difficult to challenge assumptions that were embedded in these narratives.

This tendency to preserve assumptions led to what we may call a narrow imagination that seemingly took the current state of affairs and adapted it marginally. The following quotes illustrate this tendency of simply improving elements of a given system without employing a more fundamental imagination of what the future could be (Kenyan workshop, story line development based on seeds). For example, one group said:

Participant 1: "I would suggest that we draw a scenario where everything has been improved...so we go from this we go to a better."

Participant 2: "Here we draw a training center..."

Participant 1: “...draw a big one!”

In line with literature on transformative learning and $2^{\text {nd }}$ loop learning (Pahl-wostl 2009, Taylor 2010), another kind of imagination seems to be required to grasp the underlying premises of certain narratives and reimagine them. Narrow imagination extends the systems that already exist or connects existing systems, whereas a transformative imagination is about welling up new meaning and assumptions upon which new narratives become possible (Bohm 2013).

Fig. 1B gives an example of the imagination beyond the current system as a result of the confrontation between two visions of high security. One participant initially saw security as "security services," overlaying the current context of insecurity (Kenya was in high security alert at the time of the workshop) rather than taking the imaginative leap of visualizing the region in peace. Another participant managed to take that leap, which consequently led to the final scenario reflecting the new view.

\section{KEY INSIGHTS FOR DESIGNING PROCESSES FOR TRANSFORMATIONS}

There are many views about what constitutes necessary interventions for poverty alleviation. Thus, building shared narratives that integrate various perspectives can be challenging. For example, some actors in our case saw the challenges of poverty as related to individual constraints, and asserted the need for education and empowerment promoted by external actors. Others highlighted historical social inequalities and claimed the need for structural and cultural reforms to expand people's possibilities. Based on our in-depth analysis of the communicative spaces generated by this knowledge cocreation process, we can draw three broad insights that can help inform the design of processes that may lead to shared narratives and transformative change.

First, we emphasize the importance of conceptual integration for effective knowledge cocreation - including unpacking scientists' framings. This is a widely acknowledged observation (Newell et al. 2005); however, by attending closely to the actual communicative space opened through various techniques, we were able to observe how abstract "conceptual repertoires" were sometimes developed in a group by sharing stories of lived experiences. Thus, we propose that listening and telling stories rooted in participants' lived experiences may be an important starting point to build shared conceptual repertoires. This is supported by a range of studies across disciplines that show how 
stories and narratives are a central aspect of human cognition and how people make sense of the world (Schank 1995, Clandinin 2006, Gottschall 2012). It is in a story format that participants recount prior experiences with solutions to problems and make inferences about alternative courses of action (Eckstein and Throgmorton 2003). Stories play an important role in grounding concepts and making them understandable to different people. It is through stories that people reveal the concrete realities from which they draw the meanings of a concept. Also, through stories, concepts can become "multidimensional" as they embrace multiple meanings (Lakoff and Johnson 1999).

Secondly, designing interventions for developing transformative ideas relies on peoples' assumptions of how a system works. It is based on a sense of the dynamics of a system that decision-makers choose one intervention over another, and how they understand which intervention is more likely to achieve a certain goal. We have demonstrated how different metaphorical associations can generate different understandings of the dynamics of a socialecological system. Therefore, spending time on the coconstruction of shared metaphors and reflecting on how they shape a group's understanding is key. Based on our observations, we concur with Newell's (2012) suggestion that transdisciplinary groups should spend time analyzing metaphors related to key terms (using idea analysis [Lakoff and Johnson 1999], for example) as part of the initial steps of knowledge integration.

Thirdly, as participants develop shared understanding and jointly frame the challenges of a specific social-ecological context, they may create the foundation on which to build shared narratives for galvanizing collective action (Meijerink and Huitema 2010, Goldstein et al. 2015). We found that it is challenging to break away from existing social-ecological narratives. Even when exploring new futures, there is tendency to imagine incremental change in existing systems rather than imagining new assumptions for fundamentally new systems. The tools explored here appeared to favor a narrow rather than transformative imagination of $2^{\text {nd }}$ loop learning (Pahl-wostl 2009).

Transforming social-ecological relations is also about shifts in power structures (Moore and Westley 2011, Brown et al. 2013). Although in this article we do not focus on the issue of power, it is important to note that in many contexts, the configurations of knowledge and narratives can be intrinsically linked to power dynamics (Stirling 2007). The knowledge cocreation process that was analyzed sought to mitigate power plays among participants by design (using breakout groups, balancing gender and space for contributions), but it is not possible to exclude power relations between participants. Following from our observations, devoting attention to the coconstruction of meanings, narratives, and assumptions and who defines them may be one way to mitigate some of the effects of power.

In line with other studies, we also observed that the choice and application of technique has an impact on creativity and imagination of a group (van Vliet et al. 2012). Our analysis has detailed those findings in at least two ways. First, we were able to uncover how techniques encouraged thinking at different levels of abstraction. System diagrams favored conversations based on abstract concepts, which in instances arguably limited the integration of multiple understandings. The considerable time required to build a shared conceptual repertoire may be a necessary cost for effective communication and increased systemic understanding. Secondly, our results suggest that combining storytelling processes and an increased focus on dialogue rather than on particular artifacts (system diagrams or scenario story lines) may improve imagination of novel assumptions.

We also speculate about the potential trade-off between having a wide range of topics for discussion (as was this case) and a more "focused dialogue" around specific "nexus" concepts or powerful ideas (Newell 2012, Galafassi et al. 2017). The more encompassing approach seemed in our case to reduce the deeper explorations in knowledge assumptions and dialogue.

Scientists who conducted the process we analyzed were "trained" in the methodology, hired a professional facilitator, designed the process rigorously, and in fact reached the end with the intended outcomes (systems diagrams, scenarios, list of "stress-tested" interventions). By certain standards, indeed the process can be seen as successful. Yet, the limited range of new ideas might suggest a lower influence in a transformative sense. Knowledge cocreation is a delicate process that may seem at times somewhat inefficient. However, there are examples, such as those reported by Kahane (2012), which suggest that it is possible to develop truly transformative processes. Further, recent literature on codesign suggests that despite the constraints of time and resources, transformative processes need to embrace more explicitly less clearly defined outcomes of personal transformations; e.g., changes in mental models and narratives, in order to develop, in the long run, the basis for larger institutional change (Tàbara and Ilhan 2008, Wiek et al. 2012, Page et al. 2016).

Knowledge cocreation, in which researchers and participants develop shared understandings and develop new ideas, has been heralded as a plausible strategy for supporting transformations to new social-ecological trajectories (van der Hel 2016). By taking the metaphor of weaving and using our insights we can conceptualize knowledge cocreation in three movements: unravelling, meshing, and ravelling (Fig. 2). Knowledge cocreation begins with unravelling as participants explore the histories, images, narratives, and assumptions from the different knowledges that come into the process. This process is not only of analysis but primarily of listening, telling, and sharing meaning. The second process is meshing. It is where novel ideas and concepts emerge and how insights connect to one another. This is not about integration, as in the sense of merging together different knowledges, but it is rather a process of finding ways to thread them together (Ingold 2011). Eventually, knowledge cocreation may move toward a ravelling stage, where shared meanings can shape new social-ecological narratives in the collective process of finding better ways of navigating transformations. These three stages are not equivalent to the beginning, middle, and end of a workshop, but rather they can happen throughout the span of a conversation. However, our results seem to suggest that there is a sequence of these three movements. By reading our findings through this metaphor, the limited meshing and ravelling observed (lack of novel socialecological narratives) might be explained by difficulties of unravelling of various knowledge sources (the limited shared meaning created around key concepts). 
Fig. 2. Three key processes in knowledge cocreation.

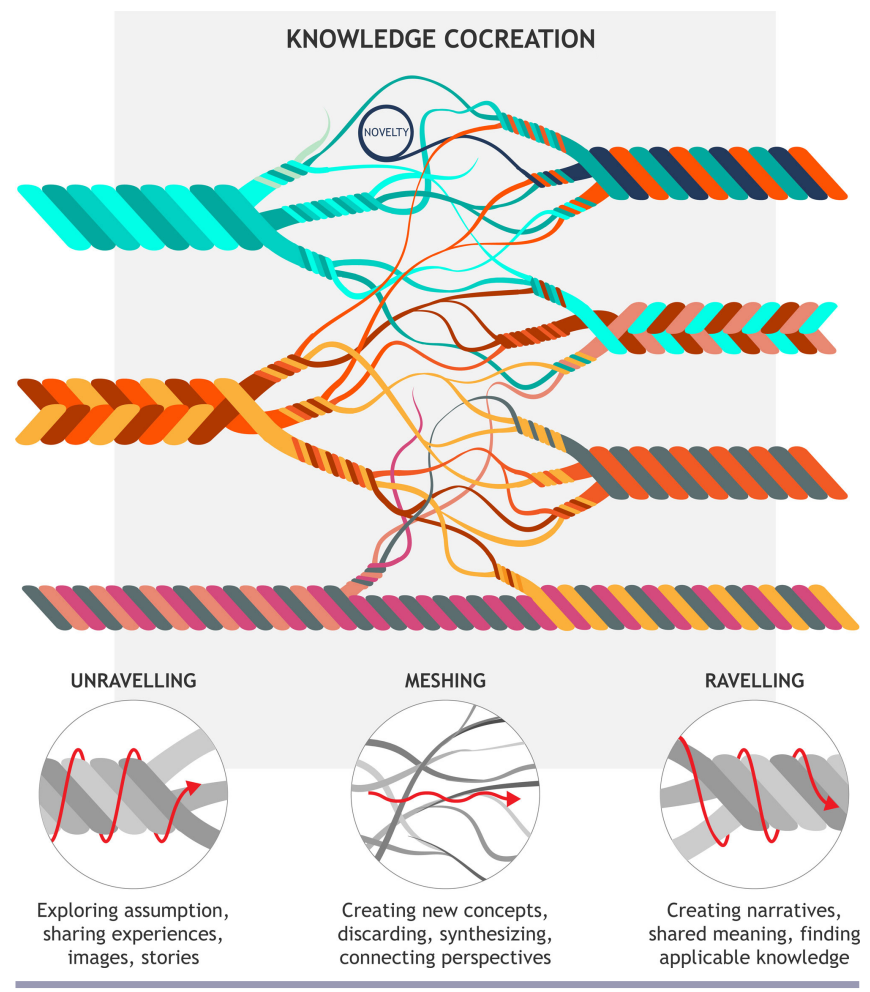

This relates closely to a multi-evidence base approach (Tengö et al. 2017) that acknowledges how knowledge systems crossfertilize and intermingle with one another. We align with the concerns expressed about the risk of power dynamics compromising the process and the need to create "bridges" rather than "integration" (Johnson et al. 2015). We acknowledge that preserving the integrity of knowledge systems is particularly important in political platforms such as international sciencepolicy processes, as treated by Tengö et al. (2017). However, in the context of transformations, some of the knowledge and values that are relevant for anticipating and shaping new socialecological interventions is not yet held by any single group but may emerge in open, transparent, cocreative, and imaginative spaces as diverse groups of people seek to grapple with the unfolding challenges.

\section{CONCLUSION}

How societies narrate poverty and its dynamics within socialecological realities matters for how interventions are imagined and implemented within future pathways. We demonstrated some of the challenges of knowledge cocreation in fostering shared conceptual repertoires and supporting the inquiry into key assumptions that lock in particular social-ecological dynamics. Exploring key assumptions is key to rupturing well-established and rehearsed narratives and to opening creative opportunities for new types of action and collaboration.

Knowledge cocreation is promoted as an important strategy in transformations toward sustainability (Mauser 2013). The extent to which these processes lead to new ways of framing problems and the development of innovations is still debated. We analyzed system thinking (both as diagrams and rich scenario pictures) as a particular way of understanding the complex interdependencies between poverty alleviation and ecosystems. With a close observation of the communicative spaces, our study contributes to a better understanding of how shared abstract concepts and narratives are questioned, shaped, and applied, and how they can be unpacked for deeper exchange of perspectives, synthesis, and generation of innovative ideas. Intensively facilitated participatory workshops using a range of system mapping and scenario tools can support the exchange of knowledge and understanding of challenges. But the limited time available to delve into assumptions may limit their potential to generate novelty and transformative solutions. Allowing time to explore assumptions may require processes that focus on a narrower range of questions to allow deeper investigations. One way forward may be to design spaces to be rich in narrative (Dahlstrom 2014)

We also draw attention to the persistence of dominant narratives. Even when carefully facilitated, narratives can still be perpetuated and accommodated within the processes and artifacts produced, particularly by actors with greater discursive power. Individuals with high institutional power can be seen as an asset for the process; however, knowledge cocreation needs to find ways to truly open up to multiple ways of knowing and seeing the challenges of poverty alleviation and ecosystem sustainability. That goes through not only inviting marginalized groups but also opening up expressive and communicative spaces that can embrace their perspectives. We urge the need to find approaches that engage and integrate richer forms of knowledge and experience to trigger creativity and imagination of transformative pathways.

Responses to this article can be read online at: http://www.ecologyandsociety.org/issues/responses. $\mathrm{php} / 9932$

\section{Acknowledgments:}

We are grateful to all participants of workshops in Kenya and Mozambique. The monitoring team in Kenya and Mozambique was Anne Wangari, Marlyn Omondi, Anne Kairu, Almedia Guissamulo, Anne Wanjiru, Lilian Mwikaki, Vera Julien, Dominique D'Emille, Vilma Machava, Eunice Ribeiro, Vitor Domingos, Ezidio Cuamba, and Siran Offman. SPACES team was Celia Macamo, Björn Schulte-Herbruggen, and Lilian Nyaga. We thank two anonymous reviewers, Michele-lee Moore, Maria Tengö, Laura Pereira, and Patrick van Zwanenberg for comments on early drafts. Figure 1 is a dialectogram by Mitch Miller. Figure 2 was illustrated by Jerker Lokrantz (Azote). This paper presents the results from the project "Sustainable Poverty Alleviation from Coastal Ecosystem Services" (SPACES) NE-K010484-1, funded by the Ecosystem Services for Poverty Alleviation (ESPA) programme. The ESPA programme is funded by the Department for International Development (DFID), the Economic and Social Research Council (ESRC), and the Natural Environment Research Council (NERC). DG is supported by the Strategic Research Program EkoKlim 481/4953030 at Stockholm University through the 
Swedish Research Council for Environment, Agricultural Sciences and Spatial Planning (FORMAS). TD is supported by the Sida funded programme "Guidance for Resilience in the Anthropocene: Investments for Development” (GRAID).

\section{LITERATURE CITED}

Barnaud, C., and A. Van Paassen. 2013. Equity, power games, and legitimacy: dilemmas of participatory natural resource management. Ecology and Society 18(2):21. http://dx.doi. org/10.5751/ES-05459-180221

Bennett, E. M., M. Solan, R. Biggs, T. McPhearson, A. V. Norström, P. Olsson, L. Pereira, G. D. Peterson, C. Raudsepphearne, F. Biermann, et al. 2016. Bright spots: seeds of a good Anthropocene. Frontiers in Ecology and the Environment 14:441448. http://dx.doi.org/10.1002/fee.1309

Bohm, D. 2013. On dialogue. Routledge.

Brown, K., S. O'Neill, and C. Fabricius. 2013. Social science understandings of transformation. Pages 100-106 in World social science report 2013: changing global environments. OECD Publishing and UNESCO Publishing. http://dx.doi. org/10.1787/9789264203419-13-en

Carpenter, S. R., E. M. Bennett, and G. D. Peterson. 2006. Scenarios for ecosystem services: an overview. Ecology and Society 11(1):29. http://dx.doi.org/10.5751/ES-01610-110129

Clandinin, D. J. 2006. Handbook of narrative inquiry: mapping a methodology. Sage Publications. http://dx.doi.org/10.4135/9781452226552

Dahlstrom, M. F. 2014. Using narratives and storytelling to communicate science with nonexpert audiences. Proceedings of the National Academy of Sciences of the United States of America 111:13614-13620. http://dx.doi.org/10.1073/pnas.1320645111

Daré, W., A. Van Paassen, R. Ducrot, R. Mathevet, J. Queste, G. Trébuil, C. Barnaud, and E. Lagabrielle. 2013. Learning about interdependencies and dynamics. Pages 233-262 in M. Étienne, editor. Companion modelling: a participatory approach to support sustainable development. Springer, Dordrecht, Netherlands. http://dx.doi.org/10.1007/978-94-017-8557-0_10

Denzin, N. K, and Y. S. Lincoln. 2011. The Sage handbook of qualitative research. Sage Publications.

Eckstein, B. J., and J. A. Throgmorton, editors. 2003. Story and sustainability: planning, practice, and possibility for American cities. MIT Press.

Étienne, M. 2011. Companion modelling: a participatory approach to support sustainable development. Editions Quae, Versailles, France. http://dx.doi.org/10.1007/978-94-017-8557-0

Fauconnier, G., and M. Turner. 2008. The way we think: conceptual blending and the mind's hidden complexities. Basic Books.

Fazey, I., L. Bunse, J. Msika, M. Pinke, K. Preedy, A. C. Evely, E. Lambert, E. Hastings, S. Morris, and M. S. Reed. 2014. Evaluating knowledge exchange in interdisciplinary and multistakeholder research. Global Environmental Change 25:204-220. http://dx.doi.org/10.1016/j.gloenvcha.2013.12.012
Fazey, I., J. A. Fazey, D. M. A. Fazey. 2005. Learning more effectively from experience. Ecology and Society 10(2):4. http:// dx.doi.org/10.5751/ES-01384-100204

Fazey, I., P. Moug, S. Allen, K. Beckmann, D. Blackwood, M. Bonaventura, K. Burnett, M. Danson, R. Falconer, A. S. Gagnon, R. Harkness, A. Hodgson, L. Holm, K. N. Irvine, R. Low, C. Lyon, A. Moss, A. Moran, L. Naylor, K. O'Brien, S. Russell, S. Skerratt, J. Rao-Williams, and R. Wolstenholme. 2017. Transformation in a changing climate: a research agenda. Climate and Development 0(0):1-21.

Flyvbjerg, B., and S. Sampson. 2009. Making social science matter. Cambridge University Press.

Folke, C., A. Jansson, J. Rockström, P. Olsson, S. R. Carpenter, F. S. Chapin, A. Crepin, et al. 2011. Reconnecting to the biosphere. Ambio (40):719-738. http://dx.doi.org/10.1007/s13280-011-0184$\mathrm{y}$

Galafassi, D., T. M. Daw, L. Munyi, K. Brown, C. Barnaud, and I. Fazey. 2017. Learning about social-ecological trade-offs. Ecology and Society 22(1):2. http://dx.doi.org/10.5751/ES-08920-220102

Goldstein, B. E., A. T. Wessells, R. Lejano, and W. Butler. 2015. Narrating resilience: transforming urban systems through collaborative storytelling. Urban Studies 52:1285-1303. http://dx. doi.org/10.1177/0042098013505653

Gottschall, J. 2012. The storytelling animal: how stories make us human. Houghton Mifflin Harcourt.

Huitema, D., and S. Meijerink. 2010. Realizing water transitions: the role of policy entrepreneurs in water policy change. Ecology and Society 15(2):26. http://dx.doi.org/10.5751/ES-03488-150226

Ingold, T. 2011. Being alive: essays on movement, knowledge and description. Taylor \& Francis.

Järnberg, L. 2016. Linking sustainable ecosystem services to human well-being in policy. SPACES Working Paper Series No. 002 .

Jetter, A. J., and K. Kok. 2014. Fuzzy Cognitive Maps for futures studies - a methodological assessment of concepts and methods. Futures 61:45-57. http://dx.doi.org/10.1016/j.futures.2014.05.002

Johnson, J. T., R. Howitt, G. Cajete, F. Berkes, R. L. Louis, and A. Kliskey. 2015. Weaving Indigenous and sustainability sciences to diversify our methods. Sustainability Science 11(1):1-11.

Kahane, A. 2012. Transformative scenario planning: working together to change the future. Berrett-Koehler Publishers.

Kegan, R., and L. L. Lahey. 2009. Immunity to change: how to overcome it and unlock potential in yourself and your organization. Harvard Business Press.

Kok, K., and H. van Delden. 2004. Linking narrative storylines and quantitative models to combat desertification in the Guadalentín, Watershed (Spain). Pages 203-214 in M. Giaoutzi and B. Sapio, editors. Recent developments in foresight methodologies. Complex Networks and Dynamic Systems. Vol 1. Springer, Boston, Massachuesetts, USA. http://dx.doi. org/10.1007/978-1-4614-5215-7_13 
Krueger, R. A., and M. A. Casey. 2014. Focus groups: a practical guide for applied research. Sage Publications.

Lakoff, G., and M. Johnson. 1999. Philosophy in the flesh: the embodied mind and its challenge to Western thought. Basic Books, New York, USA.

Leach, M., I. Scoones, and A. Stirling. 2010. Dynamic sustainabilities: technology, environment, social justice. Earthscan.

Lotz-Sisitka, H., M. Belay Ali, G. Mphepo, M. Chaves, T. Macintyre, T. Pesanayi, A. Wals, et al. 2016. Co-designing research on transgressive learning in times of climate change. Current Opinion in Environmental Sustainability 20:50-55. http:// dx.doi.org/10.1016/j.cosust.2016.04.004

Lynam, T., and K. Brown. 2012. Mental models in humanenvironment interactions: theory, policy implications, and methodological explorations. Ecology and Society 17(3):24. http://dx.doi.org/10.5751/ES-04257-170324

Mauser, W., G. Klepper, M. Rice, B. S. Schmalzbauer, H. Hackmann, R. Leemans, and H. Moore. 2013. Transdisciplinary global change research: the co-creation of knowledge for sustainability. Current Opinion in Environmental Sustainability 5 (3-4):420-431. http://dx.doi.org/10.1016/j.cosust.2013.07.001

Meijerink, S., and D. Huitema. 2010. Policy entrepreneurs and change strategies: lessons from sixteen case studies of water transitions around the globe. Ecology and Society 15(2):21. http:// dx.doi.org/10.5751/ES-03509-150221

Ministério de Economia e Finanças (MEF). 2016. Pobreza e bemestar em Moçambique: Quarta avaliação nacional - IOF 2014/15)

Moore, M.-L., D. Riddell, and D. Vocisano. 2015. Scaling out, scaling up, scaling deep: strategies of non-profits in advancing systemic social innovation. Journal of Corporate Citizenship 2015 (58):67-84. http://dx.doi.org/10.9774/GLEAF.4700.2015.ju.00009

Moore, M., O. Tjornbo, E. Enfors, C. Knapp, J. Hodbod, J. A. Baggio, A. Norström, P. Olsson, and D. Biggs. 2014. Studying the complexity of change: toward an analytical framework for understanding deliberate social-ecological transformations. Ecology and Society 19(4):54. http://dx.doi.org/10.5751/ ES-06966-190454

Moore, M., and F. Westley. 2011. Surmountable chasms: networks and social innovation for resilient systems. Ecology and Society 16(1):1-13. [online] URL: http://www.ecologyandsociety. org/vol16/iss 1/art5/

Moser, S. C. 2016. Can science on transformation transform science? Lessons from co-design. Current Opinion in Environmental Sustainability 20:106-115. http://dx.doi.org/10.1016/ j.cosust.2016.10.007

Newell, B. 2012. Simple models, powerful ideas: towards effective integrative practice. Global Environmental Change 22(3):776-783. http://dx.doi.org/10.1016/j.gloenvcha.2012.03.006

Newell, B., C. L. Crumley, N. Hassan, E. F Lambin, C. Pahlwostl, A. Underdal, and R. Wasson. 2005. A conceptual template for integrative human-environment research. Global Environmental Change 15(4):299-307. http://dx.doi.org/10.1016/j.gloenvcha.2005.06.003
O'Brien, K., and L. Sygna. 2013. Responding to climate change: the three spheres of transformation. Pages 16-23 in Proceedings of Transformation in a Changing Climate, 19-21 June 2013, University of Oslo, Oslo, Norway.

Olsson, P., V. Galaz, and W. J. Boonstra. 2014. Sustainability transformations: a resilience perspective. Ecology and Society 19 (4):1. http://dx.doi.org/10.5751/ES-06799-190401

Oteros-Rozas, E., B. Martin-Lopez, T. M. Daw, E. L. Bohensky, J. R. A. Butler, R. Hill, J. Martin-Ortega, A. Quinlan, F. Ravera, I. Ruiz-Mallén, M. Thyresson, J. Mistry, I. Palomo, G. D. Peterson, T. Plieninger, K. A. Waylen, D. M. Beach, I. C. Bohnet, M. Hamann, J. Hanspach, K. Hubacek, S. Lavorel, and S. P. Vilardy. 2015. Participatory scenario planning in place-based social-ecological research: insights and experiences from 23 case studies. Ecology and Society 20(4):32. http://dx.doi.org/10.5751/ ES-07985-200432

Page, G. G., R. M. Wise, L. Lindenfeld, P. Moug, A. Hodgson, C. Wyborn, and I. Fazey. 2016. Co-designing transformation research: lessons learned from research on deliberate practices for transformation. Current Opinion in Environmental Sustainability 20:86-92. http://dx.doi.org/10.1016/j.cosust.2016.09.001

Pahl-wostl, C. 2009. A conceptual framework for analysing adaptive capacity and multi-level learning processes in resource governance regimes. Global Environmental Change 19:354-365. http://dx.doi.org/10.1016/j.gloenvcha.2009.06.001

Patton, M. Q. 2014. Qualitative research \& evaluation methods. Fourth edition. SAGE Publications.

Pelling, M., K. O'Brien, and D. Matyas. 2014. Adaptation and transformation. Climatic Change 133(1):113-127. http://dx.doi. org/10.1007/s10584-014-1303-0

Peterson, G. D., G. S. Cumming, and S. R. Carpenter. 2003. Scenario planning, a tool for conservation in an uncertain world. Conservation Ecology 17:358-366. http://dx.doi.org/10.1046/ j.1523-1739.2003.01491.x

Rosendo, S. 2016. Linking sustainable ecosystem services to human well-being in policy: a review of Mozambican policies and strategies. SPACES Working Paper Series No. 001.

Schank, R. C. 1995. Tell me a story: narrative and intelligence. Northwestern University Press, Evanston Illinois, USA.

Sharpe, B., A. Hodgson, G. Leicester, A. Lyon, and I. Fazey. 2016. Three horizons: a pathways practice for transformation. Ecology and Society 21(2):47. http://dx.doi.org/10.5751/ES-08388-210247

SPACES. 2017. Project reports. [online] URL: http://www.espaspaces.org/resources/publications/

Steffen, W., W. Broadgate, L. Deutsch, O. Gaffney, and C Ludwig. 2015. The trajectory of the Anthropocene: the Great Acceleration. Anthropocene Review 2:81-98. http://dx.doi. org/10.1177/2053019614564785

Stirling, A., 2007. "Opening up" and "closing down": power, participation, and pluralism in the social appraisal of technology. Science, Technology, \& Human Values 33(2):262-294. http://dx. doi.org/10.1177/0162243907311265 
Tàbara, J. D., and I. Chabay. 2013. Coupling human information and knowledge systems with social-ecological systems change: reframing research, education, and policy for sustainability. Environmental Science \& Policy 28:71-81. http://dx.doi. org/10.1016/j.envsci.2012.11.005

Tàbara, J. D., and A. Ilhan. 2008. Culture as trigger for sustainability transition in the water domain: the case of the Spanish water policy and the Ebro River Basin. Regional Environmental Change 8(2):59-71. http://dx.doi:10.1007/ $\underline{\text { s10113-007-0043-3 }}$

Taylor, E. W. 2010. Transformative learning theory. In S. B. Merriam, editor. Third update on adult learning theory: new directions for adult and continuing education, Number 119. John Wiley \& Sons.

Tengö, M., E. S. Brondizio, T. Elmqvist, P. Malmer, and M. Spierenburg. 2014. Connecting diverse knowledge systems for enhanced ecosystem governance: the multiple evidence base approach. Ambio 43(5):579-591. http://dx.doi.org/10.1007/ $\underline{\text { s13280-014-0501-3 }}$

Tengö, M., R. Hill, P. Malmer, C. M. Raymond, M. Spierenburg, F. Danielsen, T. Elmqvist, and C. Folke. 2017. Weaving knowledge systems in IPBES, CBD and beyond-lessons learned for sustainability. Current Opinion in Environmental Sustainability 26-27:17-25.

van der Hel, S. 2016. New science for global sustainability? The institutionalisation of knowledge co-production in Future Earth. Environmental Science \& Policy 61:165-175. http://dx.doi. org/10.1016/j.envsci.2016.03.012

van Vliet, M., K. Kok, and T. Veldkamp. 2010. Linking stakeholders and modellers in scenario studies: the use of Fuzzy Cognitive Maps as a communication and learning tool. Futures 42(1):1-14. http://dx.doi.org/10.1016/j.futures.2009.08.005

van Vliet, M., K. Kok, A. Veldkamp, and S. Sarkki. 2012. Structure in creativity: an exploratory study to analyse the effects of structuring tools on scenario workshop results. Futures 44(8) 746-760. http://dx.doi.org/10.1016/j.futures.2012.05.002

Wenger, E. 2013. Communities of practice.

Westley, F. R., O. Tjornbo, L. Schultz, P. Olsson, C. Folke, B. Crona, and Ö. Bodin. 2013. A theory of transformative agency in linked social-ecological systems. Ecology and Society 18(3):27. http://dx.doi.org/10.5751/ES-05072-180327

Wiek, A., B. Ness, P. Schweizer-Ries, F. S. Brand, and F. Farioli. 2012. From complex systems analysis to transformational change: a comparative appraisal of sustainability science projects. Sustainability Science 7(S1):5-24. http://dx.doi.org/10.1007/ $\underline{\text { s11625-011-0148-y }}$

Wiek, A., S. Talwar, M. O’Shea, and J. Robinson. 2014. Toward a methodological scheme for capturing societal effects of participatory sustainability research. Research Evaluation 23 (2):117-132. http://dx.doi:10.1093/reseval/rvt031 


\section{Stories in social-ecological knowledge co-creation}

\section{Supplementary Material}

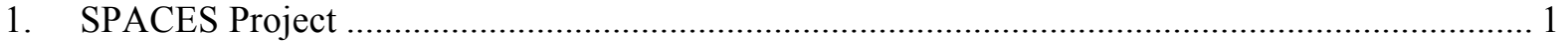

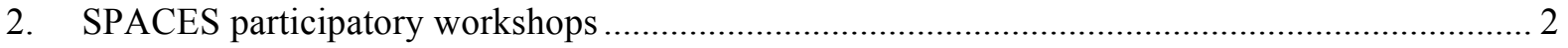

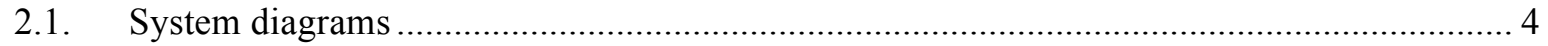

2.2. Creating stories of the future and making use of the future............................................. 5

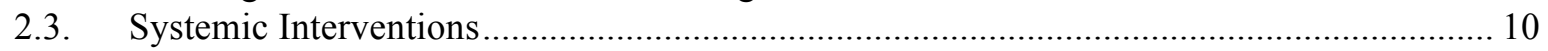

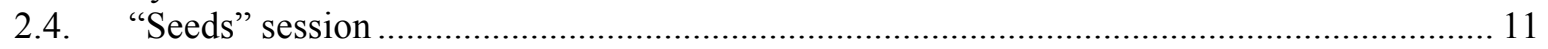

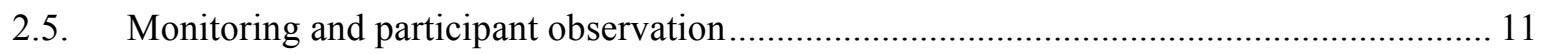

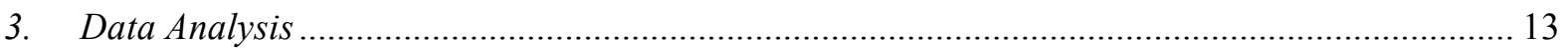

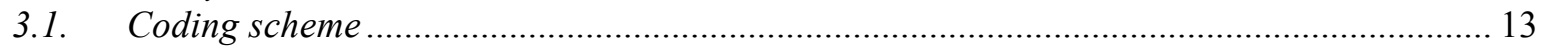

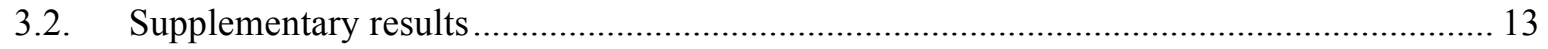

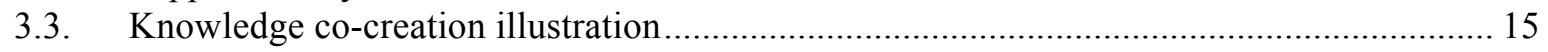

\section{SPACES Project}

The Sustainable Poverty Alleviation from Coastal Ecosystem Services (SPACES) project began in 2013 and is coming to a close at the end of August 2017. The project is supported by the UK programme, Ecosystem Services for Poverty Alleviation (ESPA). A group of scientists from Stockholm Resilience Centre (SRC), Exeter University, Lancaster University, Cambridge University, Kenya Marine \& Fisheries Research Institute (KMFRI), Kenya Forestry Research Institute (KEFRI), Wildlife Conservation Society (WCS), University of British Columbia (UBC), Northumbria University, University of East Anglia, and University Eduardo Mondlane (UEM) have joined together to study the relationship between the wellbeing of poor communities and coastal ecosystems. The project has focused on eight coastal communities in Kenya and Mozambique. The communities were chosen based on site characteristics, rural or urban/peri-urban, and the ecosystems that the communities have access to, coral reefs and/or mangroves. In Kenya (Figure S1), the four sites studied were Mombasa/Kongowea, Tsunza, Shimone/Wasini Island, and Vanga. In Mozambique (Figure S2), the four sites studied were Vamizi Island, Lalane, Maringanha, and Mieze.

Interdisciplinary research was conducted in all sites by combining both ecological and social science. The researchers investigated the state of the ecosystems by collecting mangrove and landings data, conducting underwater ecological surveys, and through Ecopath and Ecoism modeling. The team also looked at who benefits from the ecosystems through value chain analyses, an in-depth household survey, and through focus groups on access to ecosystem services. Additionally, team members 
explored how ecosystem services support wellbeing through community profiling, ecosystem service to wellbeing focus groups, and interviews. Lastly, the team studied to the future of policy and interventions in the region through policy analyses, workshop $1 \& 2$, and community dialogues.

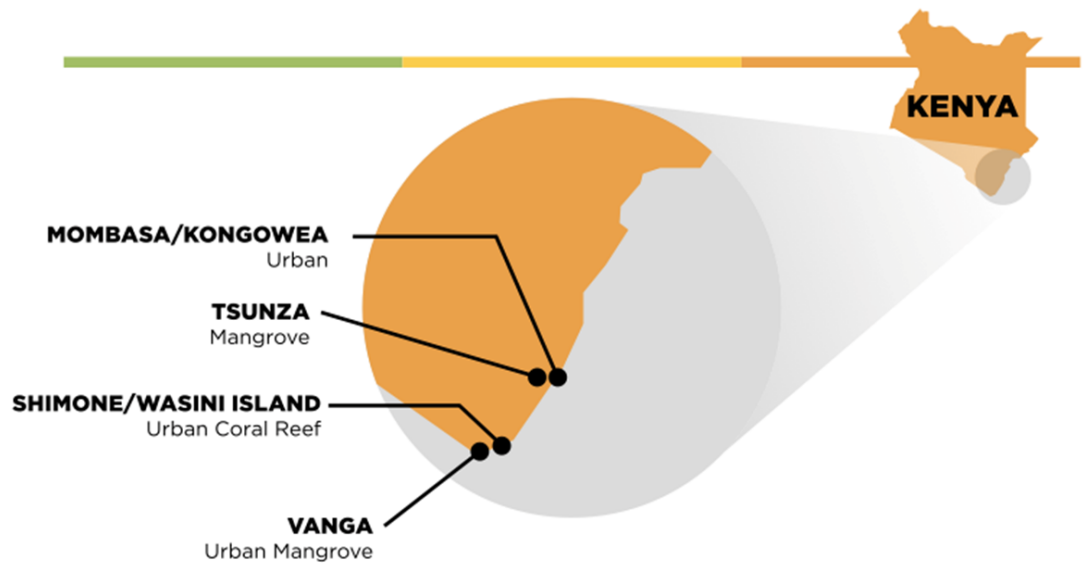

Figure S1: Map of the four sites in Kenya.

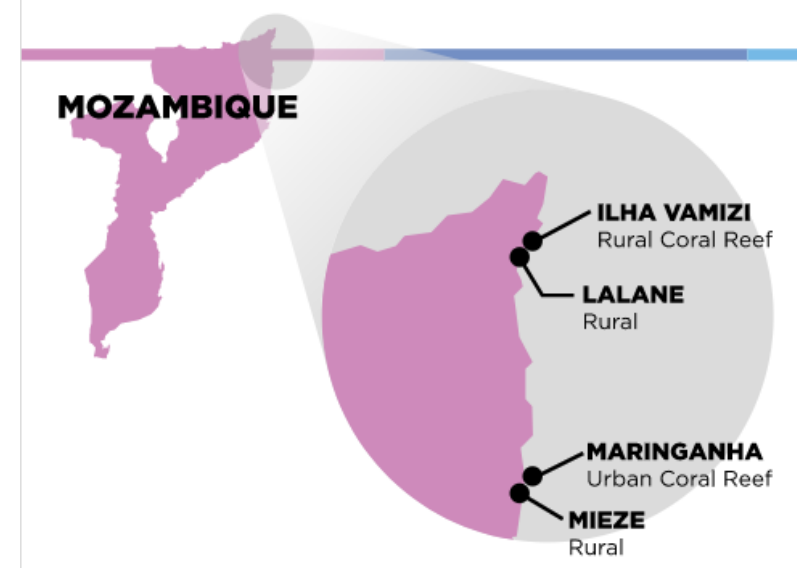

Figure S2: Map of the four sites in Mozambique.

\section{SPACES participatory workshops}

SPACES scientists developed an iterative participatory approach to enhance understanding of the coastal social-ecological systems in terms of feedback dynamics, tradeoffs and opportunities for sustainable poverty alleviation in coastal Kenya and Mozambique (SPACES 2017). Experts in the areas of poverty alleviation and sustainable resource management were brought together in a set of two participatory workshops aiming to engage stakeholders and collaboratively build systems diagrams and future scenarios to explore key dynamics of the social-ecological systems and how it might develop in the future.

The workshops used participatory modelling and scenario tools to investigate the question of: How can the coastal ecosystems of Mombasa, Kenya and Pemba, Mozambique and the benefits they provide support the well-being of the poor, now and in the future. By 'well-being' we mean having basic human needs met, and being able to pursue one's goals, and enjoy a satisfactory quality of life. It is related to concepts of happiness as well as material wealth.

Workshop one "aimed to help a range of different stakeholders and experts to share knowledge and think together about the nature and development of poverty and environment" (KE_Report WS1 
Report: 4). Prior to the workshop, the participants filled in a survey about challenges and solutions facing the communities. Then during the workshop, systems thinking was the method used to understand and make sense of the situation. Two tools were used to support systems thinking, systems diagrams and future scenarios. Following the workshop, exit interviews were conducted with all the participants.

Workshop 2 "aimed to: 1) Engage the stakeholders in the findings from the SPACES project. 2) Explore how human well-being and the ecosystem health might change in different future scenarios. 3) Identify interventions for poverty alleviation and sustainable ecosystem management and explore how they would work under different scenarios, and 4) Identify existing initiatives ("seeds") that could change the course of the scenarios" (MZ_Full Report WS2: page 2). Pre- and post- interviews were also held with the participants to understand the learning that was taking place during the workshops. Figure S3 below shows the steps of each workshop and detailed descriptions of each method used follow.

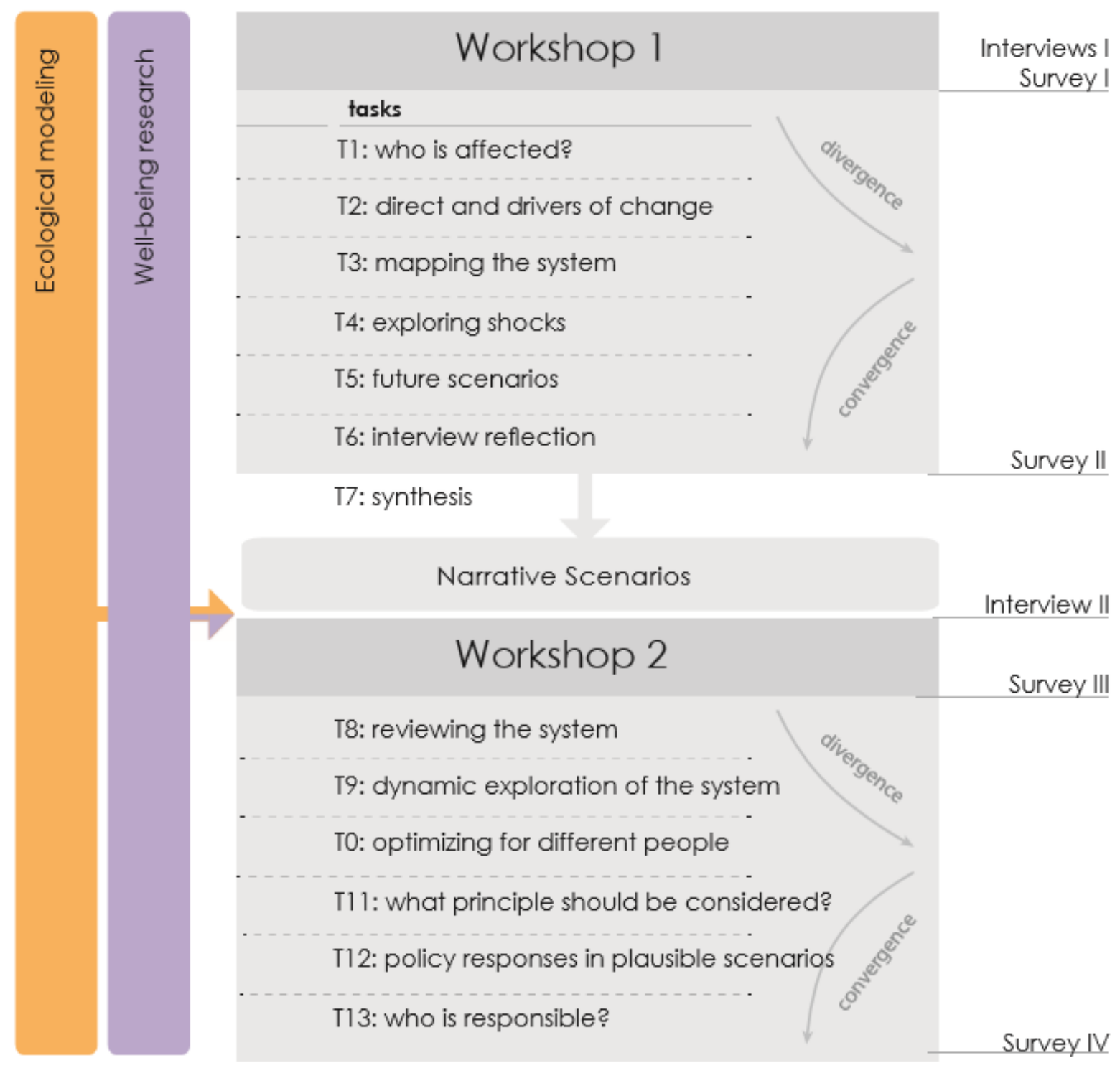

Figure S3: Chart of workshop 1 and workshop 2 


\subsection{System diagrams}

System diagrams draws on the expert knowledge of the participants at the workshop to map out a model about key factors affecting the coastal communities. This was done through a series of steps (taken from the MZ_WS1 report):

Step 1: define the problem to be addressed

Step 2: define the boundaries of the system to be described

Step 3: identify the concepts that are part of the system

Step 4: group functionally similar concepts into clusters and name the clusters

Step 5: write a glossary to describe the meaning of the concept clusters

Step 6: link the concepts and indentify the direction of interactions

Step 7: define the sign and strength of interactions

The first activity of the first workshop in both countries was conducted in groups of participants divided according to their knowledge association (community, policy-makers/government, development or conservation practitioners, scientists). Each of the 4 groups were invited to draw system diagrams with the key factors that affected the wellbeing along the coast (see Supplementary material for detailed methodology). The overall goal of this is to co-create a shared image of the main factors shaping poverty and the relations to ecosystems.

In Kenya all four groups had education in their diagrams of key factors. Governance and environmental protection also appeared in all diagrams. Interestingly, the historical and cultural issues that some participants discussed in the interviews did not feature prominently in the diagrams. Similarly, security only appeared in 1 diagram. In Mozambique, a similar pattern was found: Governance, participation and collaboration was present in all four groups as well as education and environmental protection. All of these were identified as key challenges.

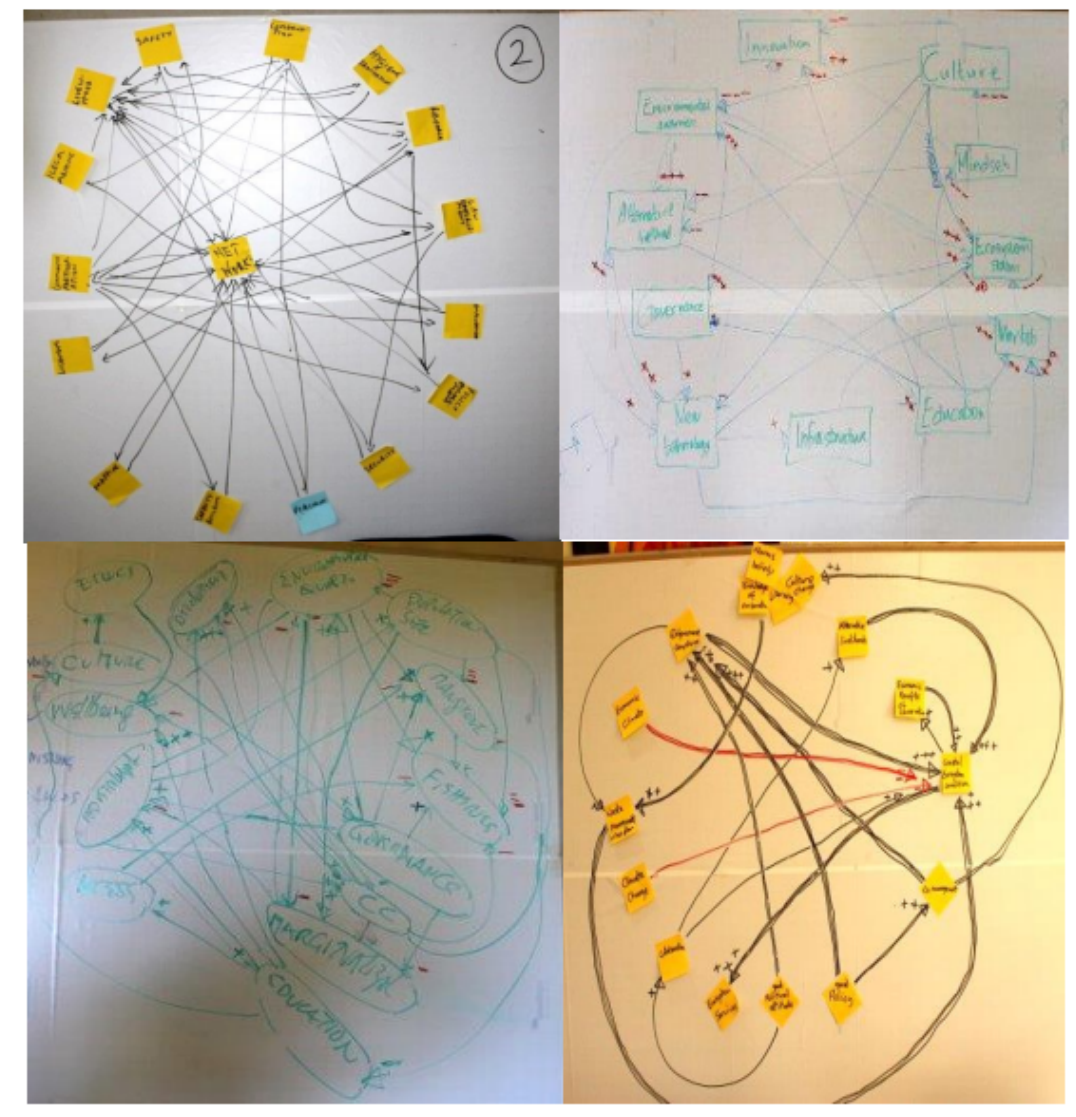

Figure S4: Pictures of the original system diagrams developed during the workshop1 in Kenya. 

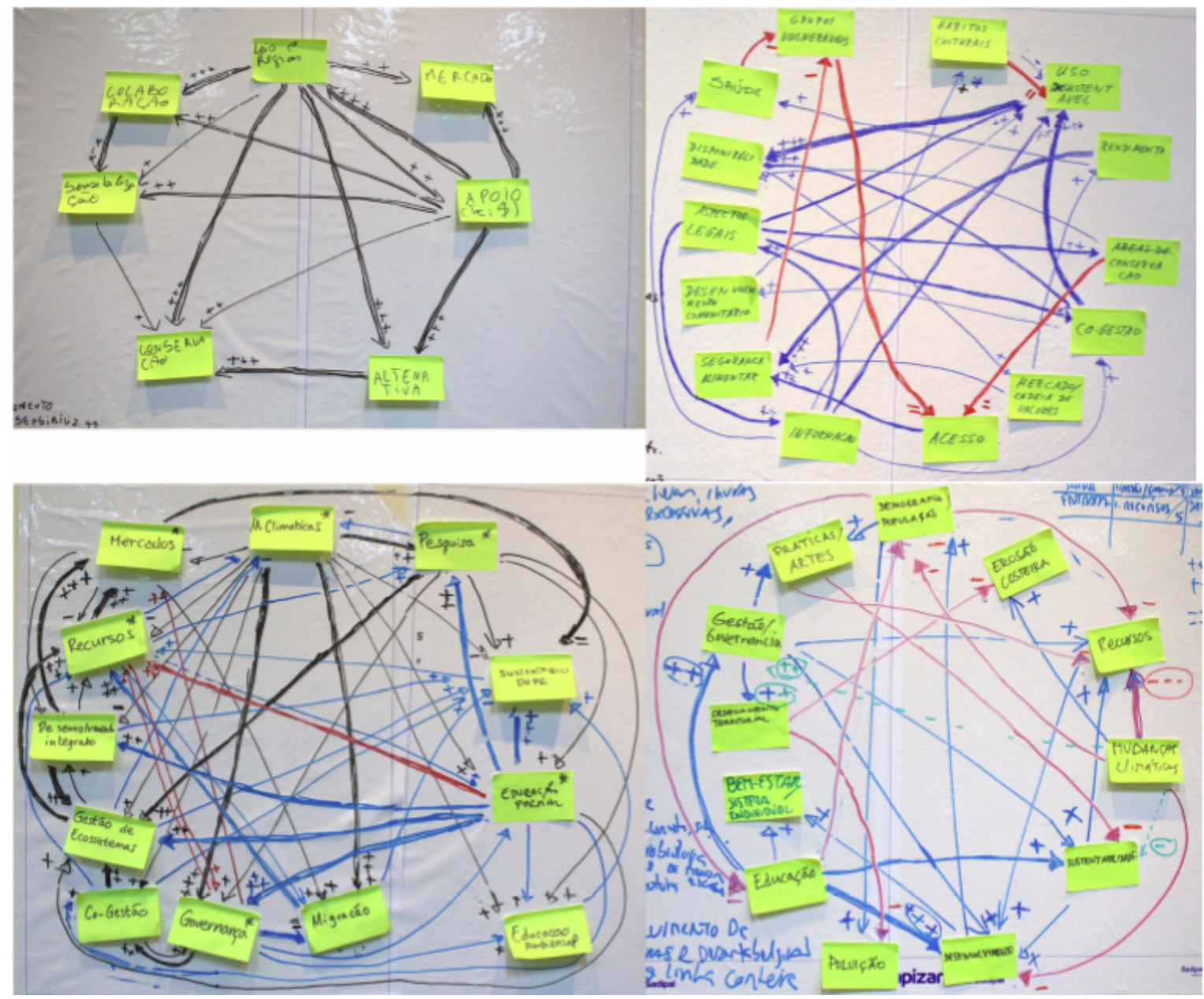

Figure S5: Pictures of the original system diagrams developed during the workshop1 in Mozambique.

\subsection{Creating stories of the future and making use of the future}

Moving on from the system diagrams, a reflection was invited around the key processes that may drive change in the coastal social-ecological system. Each participant then was invited to allocate a total of 2 votes amongst all the "driving forces" listed. From the list of most voted drivers (Table 3 ) two key drivers were selected through a plenary discussion. These two drivers represented interesting dynamics the group as a whole decided to explore in the scenarios. The two driving forces were laid out on a two axis where each quadrant represented one of the four possible combination between increase and decrease of each driving force. For example, the top right quadrant would be a scenario where both drivers would increase in intensity.

Participants sat in mixed groups to work with the combination of two key drivers. The task was to create a story of a plausible future. A total of four stories (one per group) were drafted in the first workshop. Then these stories were further developed with the consultation of a wider range of experts and finally they were illustrated by an artist and films of each narrative were produced.

Although some of these key drivers, like 'governance' or 'education' are recurrent themes in development work, we noticed that the timing and context of the workshop had some influence in saliency and perception of key drivers. In Kenya, the meeting occurred in a particular tense period where security was perceived as low - in the venue of the meeting had to be changed in order to accommodate international security recommendations. 'Security' appeared as a top driver of change. 
In Mozambique 'Gas and Oil' were not chosen as a key driver, because according to participants "the exploitation of gas and oil is stable and will continue". Interestingly, in the time between workshops (6 months) global prices of oil had declined considerably and "gas and oil" exploitation, now shadowed with uncertainty, became much more prominent during this second encounter.

Table S3. Most voted driving forces from each workshop

\begin{tabular}{|l|l|}
\hline Drivers & Votes \\
\hline Kenya & \\
\hline Governance & 10 \\
Security & 10 \\
Education & 6 \\
Community Acceptance & 4 \\
Development & 4 \\
Climate change & 3 \\
\hline Mozambique & \\
\hline Governance & 16 \\
Education & 8 \\
Climate change & 6 \\
Fishing technology & 6 \\
Development Population & 5 \\
Gas and oil & 5 \\
& 2 \\
\hline
\end{tabular}

Figures 6-13 are photos of the scenarios created by the participants in Kenya and Mozambique.

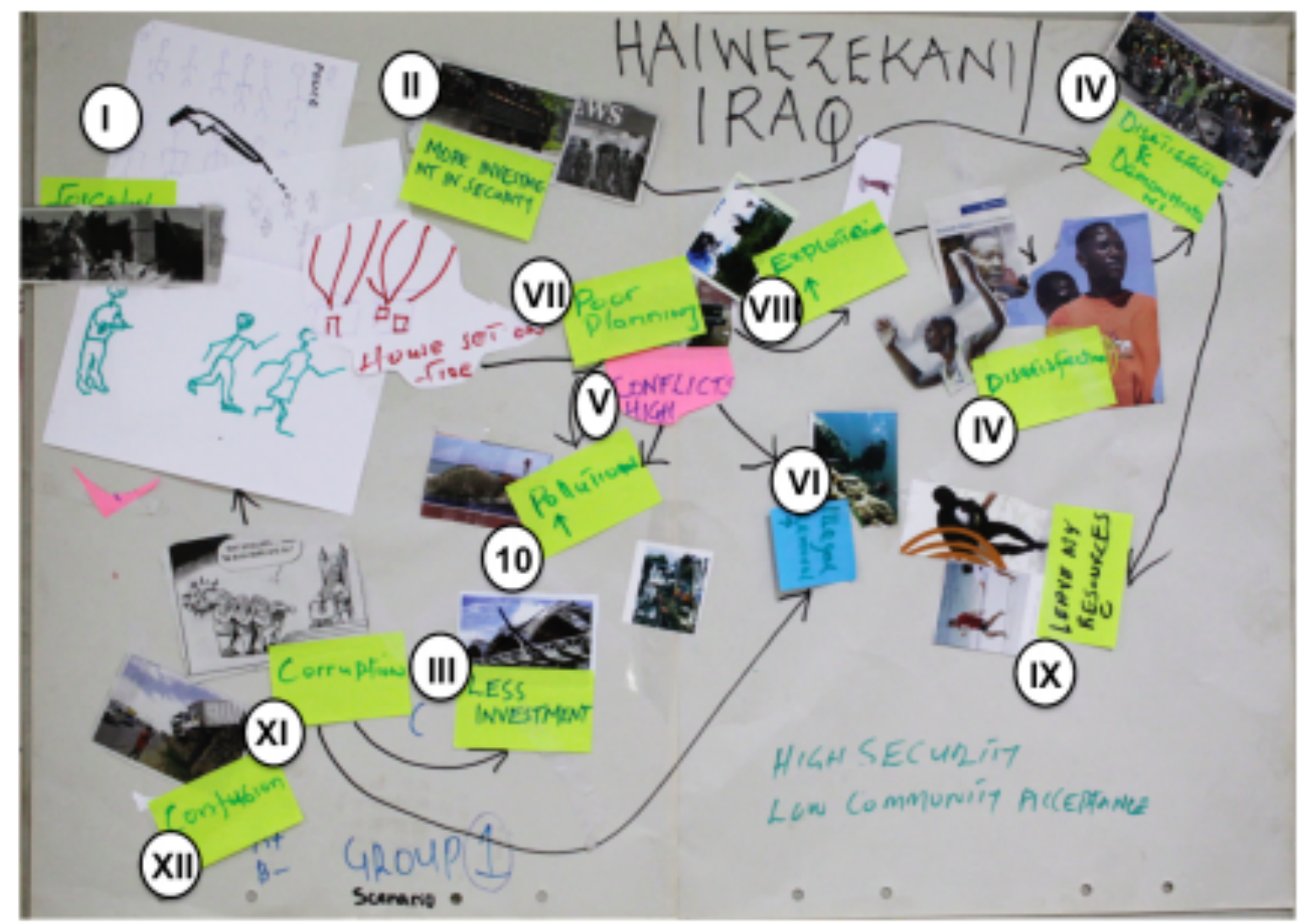

Figure S6: The scenario created by Group 1 in Kenya with the title "Haiwezekani (impossible or Iraq)" 


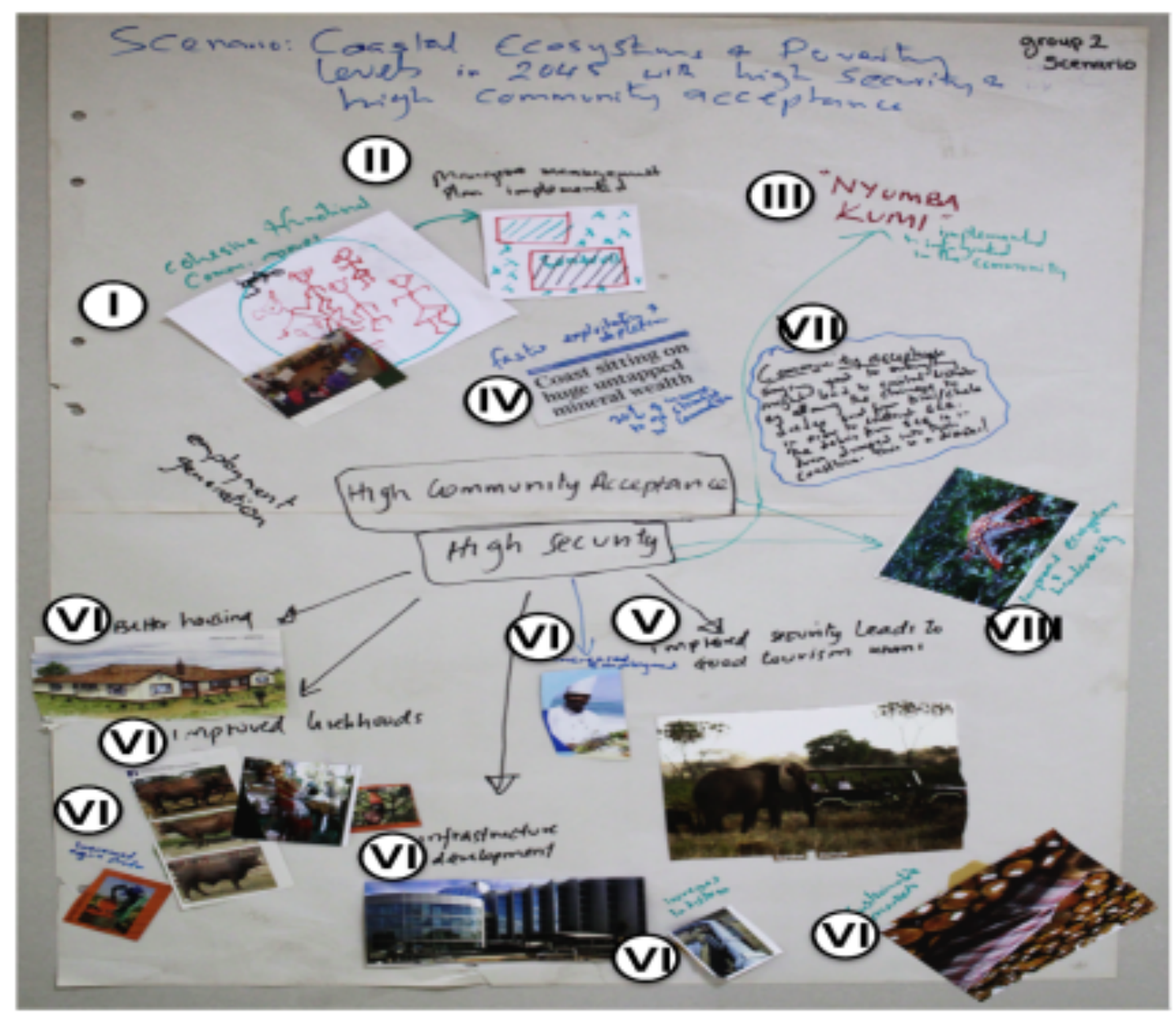

Figure S7: The scenario created by Group 2 in Kenya with the title "Coastal Ecoystems and Poverty levels in 2045 with high security and high community acceptance."

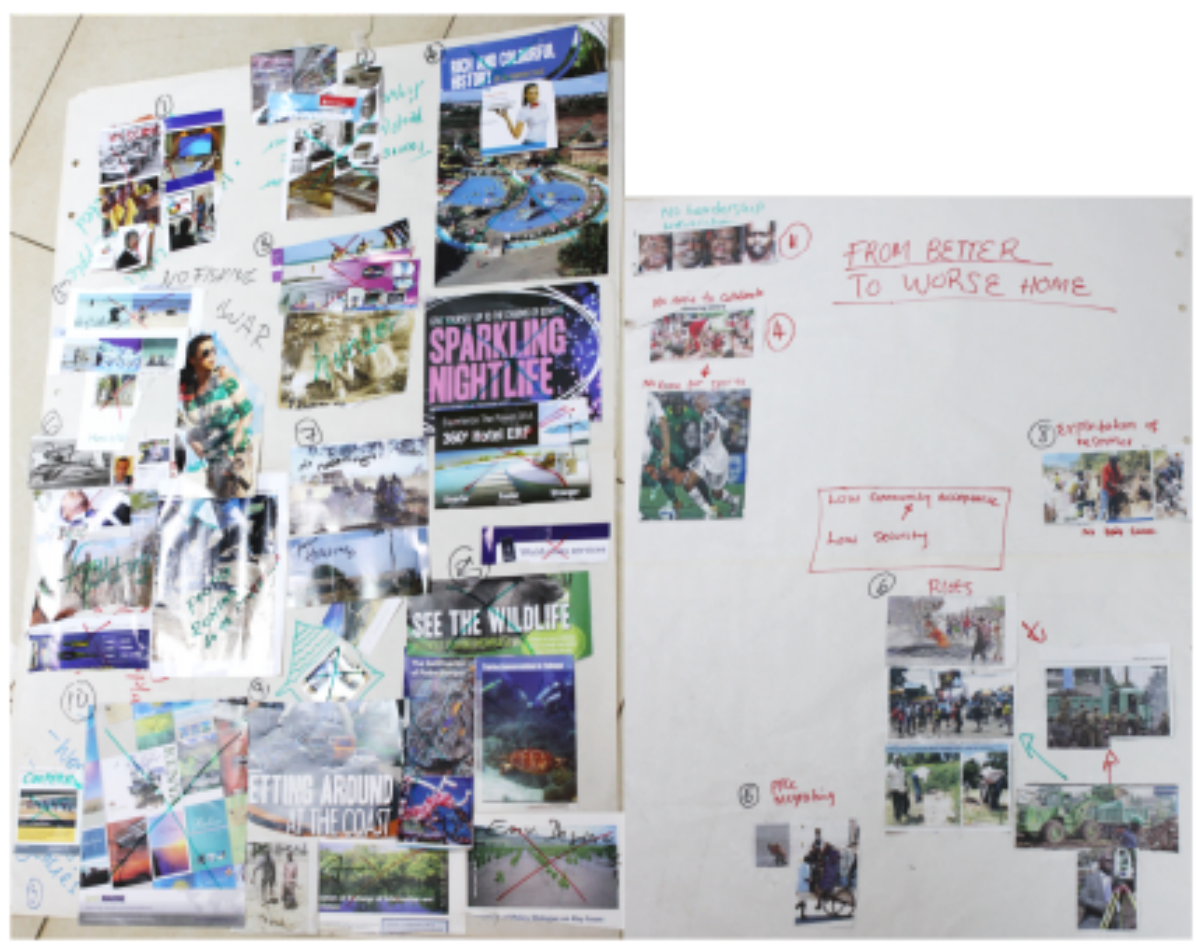

Figure S8: The scenario created by Group 3 in Kenya with the title "From better to worse home." 


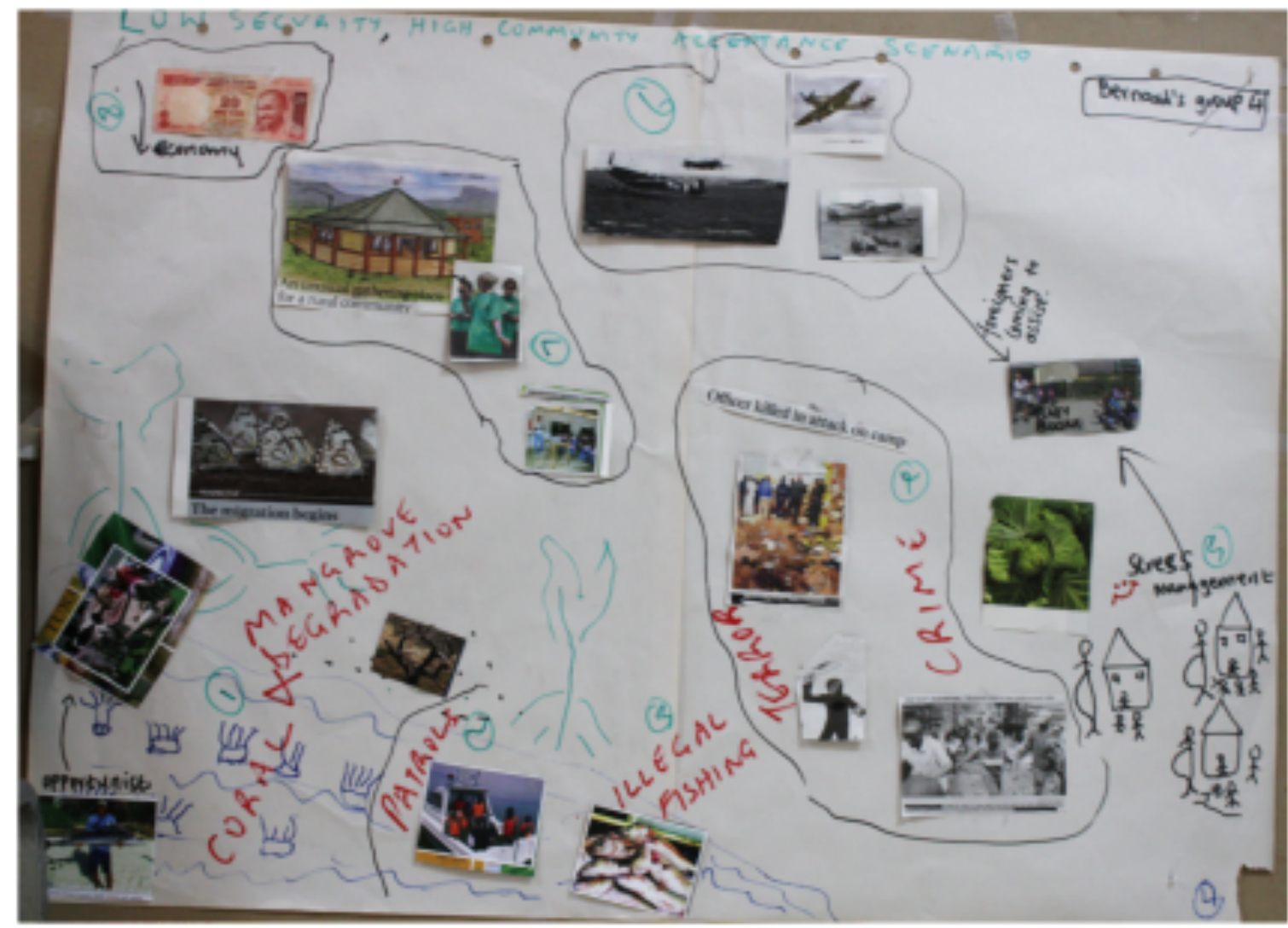

Figure S9: The scenario created by Group 4 in Kenya with the title "Low security, high community acceptance."

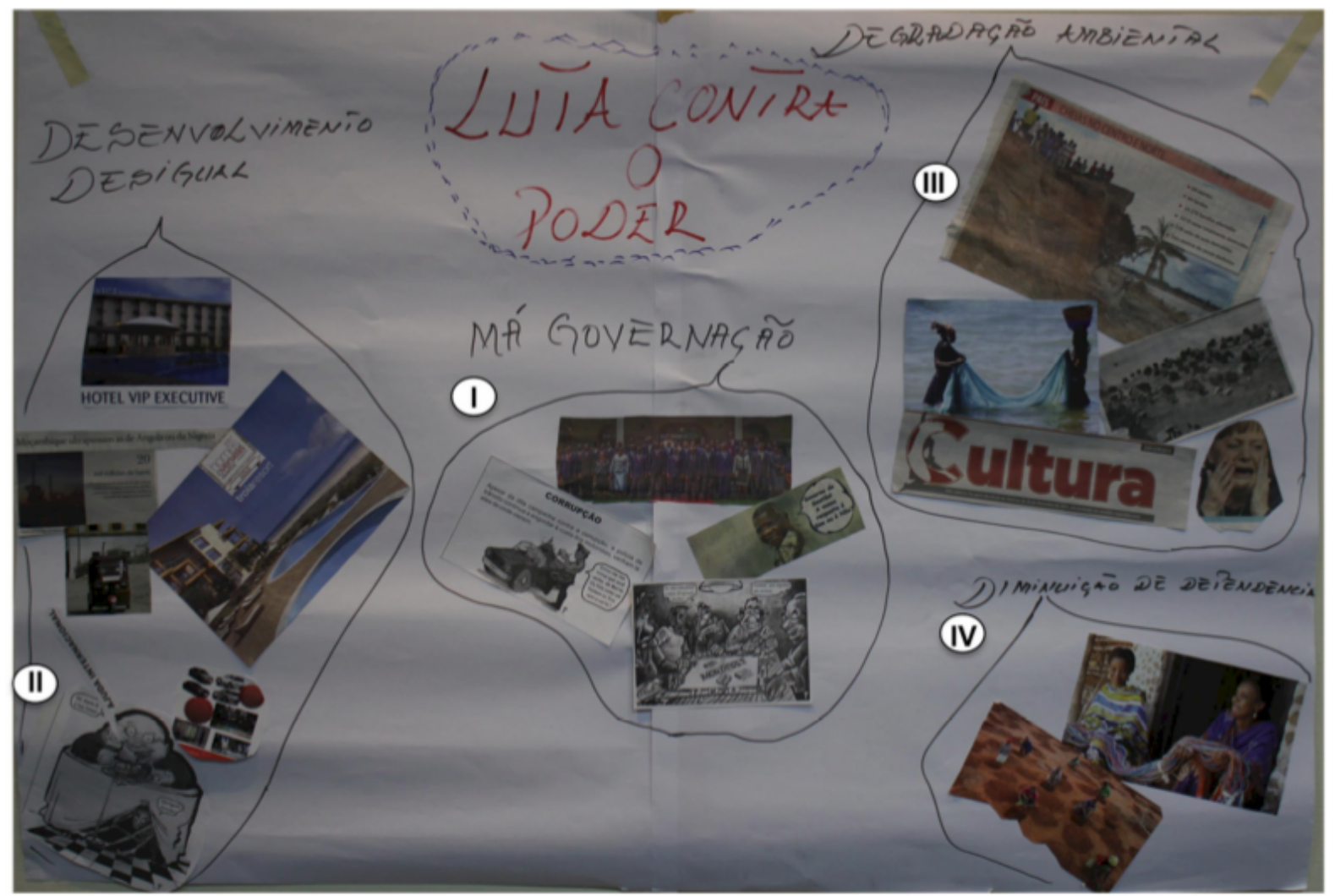

Figure S10: The scenario created by Group 1 in Mozambique with the title "Fight against the power" 


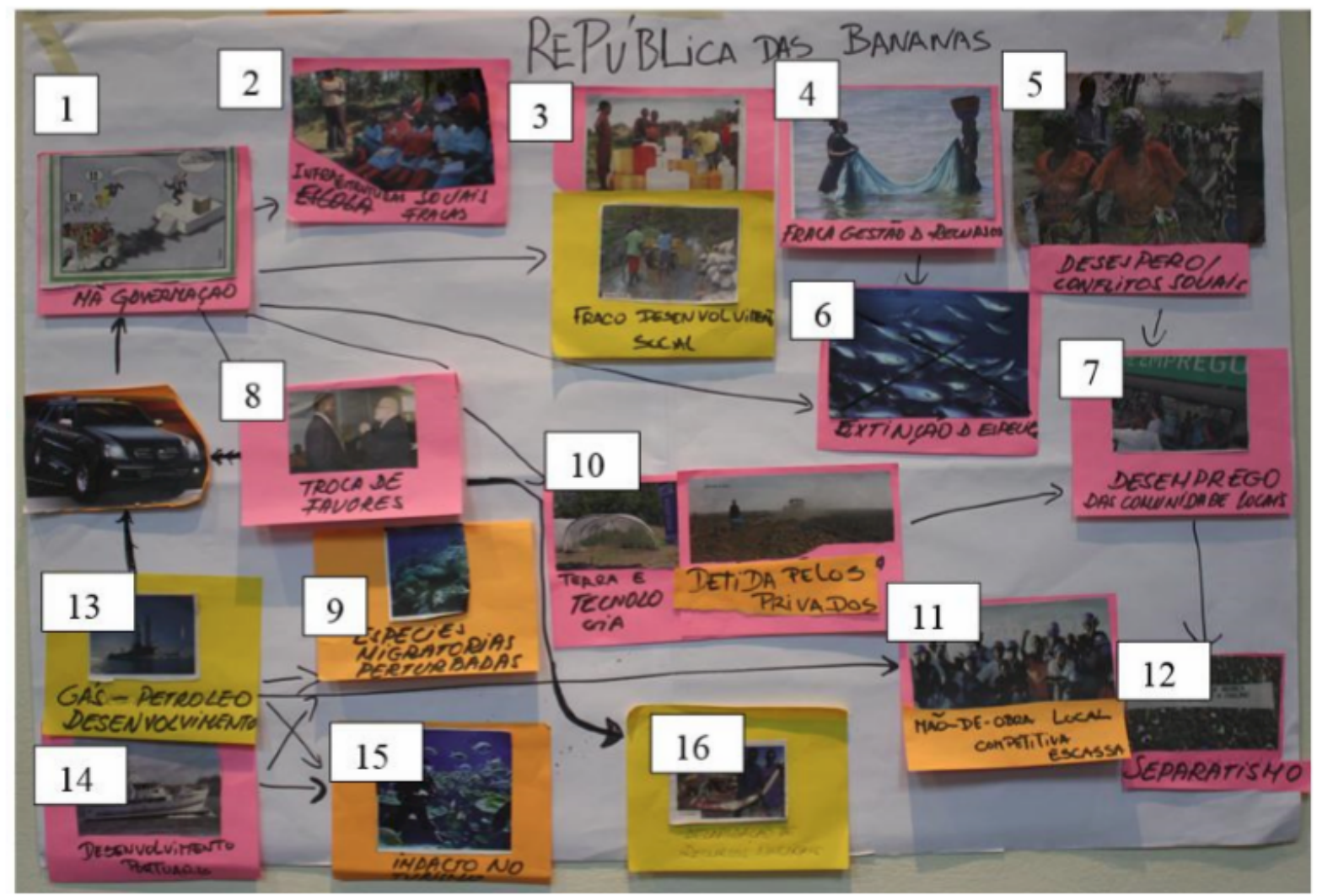

Figure S11: The scenario created by Group 2 in Mozambique with the title "Banana republic"

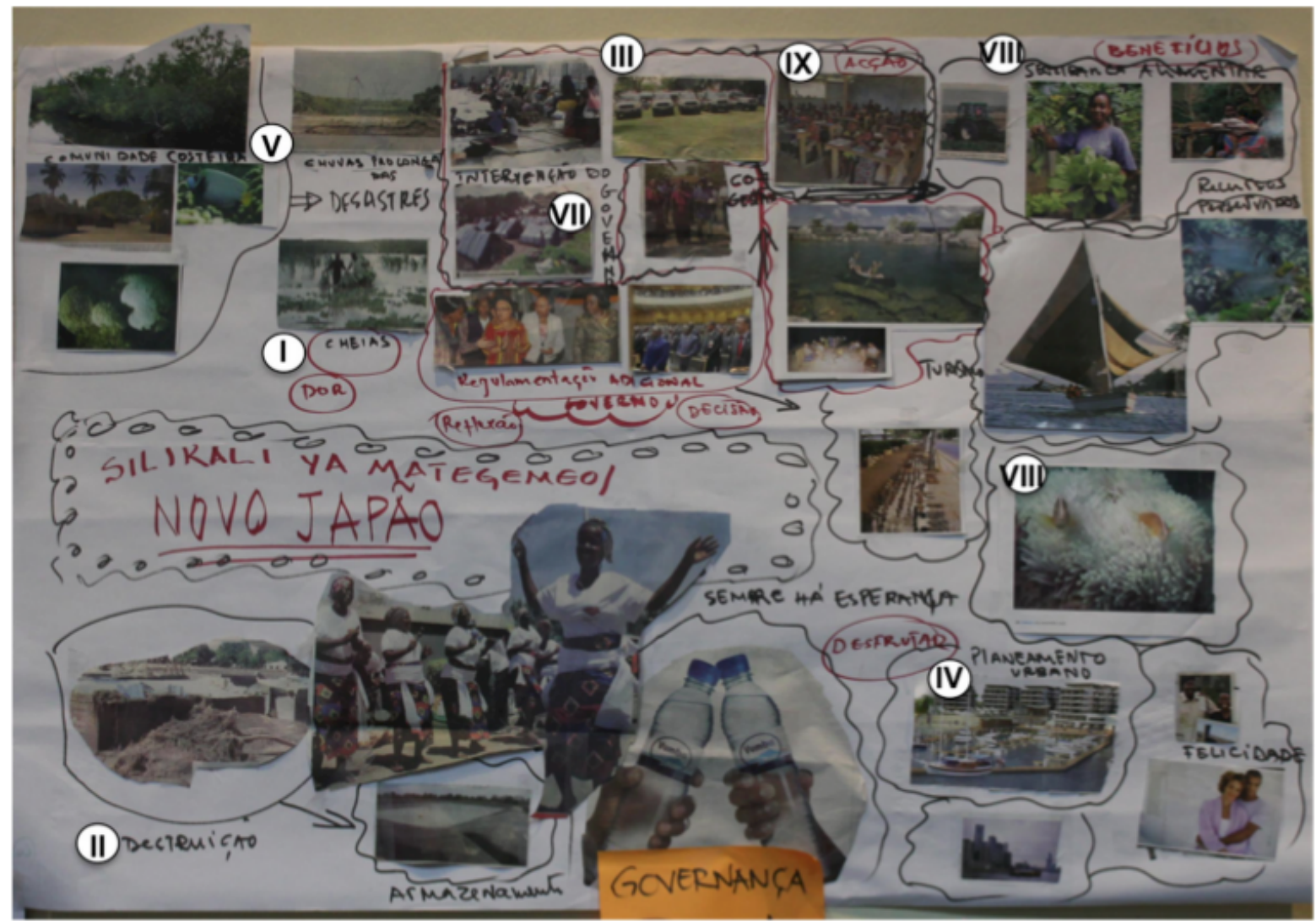

Figure S12: The scenario created by Group 3 in Mozambique with the title "New Japan/ A trustable government" 


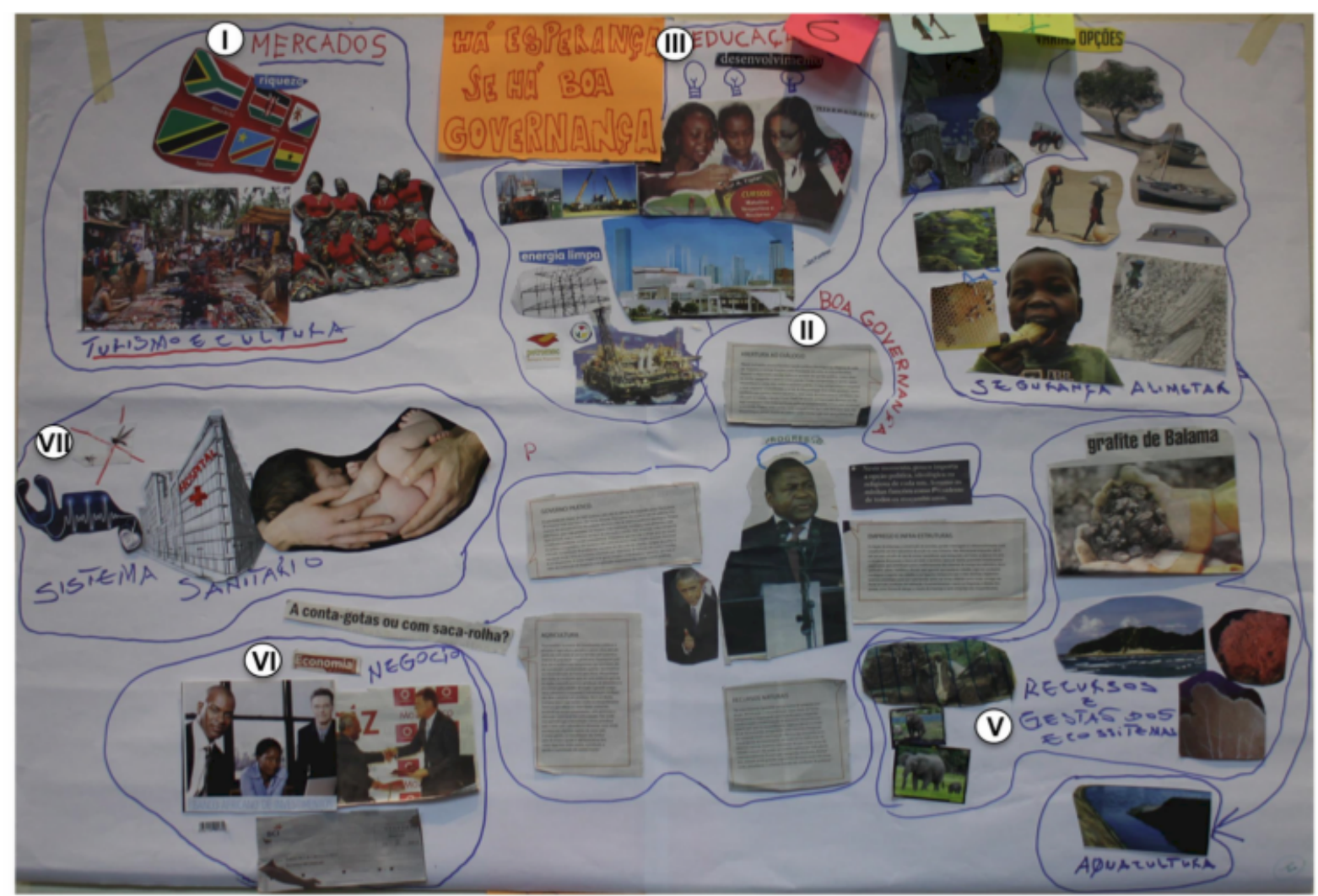

Figure S13: The scenario created by Group 4 in Mozambique with the title "There is hope if there is good governance"

\subsection{Systemic Interventions}

In the second workshop, participants were asked to identify key interventions that would improve ecosystems and poverty alleviation strategies (Table S4). The robustness of these interventions were then 'tested' in each scenario. Adjustments to the interventions were then suggested.

The following steps were taken to determine the systemic interventions:

Step 1: Revisit the stories form workshop 1

Step 2: Get familiar with narratives and bring them to life

Step 3: Name the scenarios

Step 4: Presentation on well-being research

Step 5: explore and discuss which needs were found to be frequently met or not met in rural and urban settings, and apply to scenarios

Step 6: review policies and identify interventions for poverty alleviation and sustainable ecosystem management

Step 7: Build an interventions bank with suggestion from participants

Step 8: Stress-test interventions

Table S4. Most voted policy interventions identified by participants in each country

\begin{tabular}{|l|l|}
\hline Kenya & Mozambique \\
\hline Implementation of conservation areas & $\begin{array}{l}\text { Sensitization and training of fisherfolk to adopt } \\
\text { better fishing practices }\end{array}$ \\
Implementation of participatory forest & $\begin{array}{l}\text { Development of monitoring system and } \\
\text { coordination across governance actors } \\
\text { Ensure ban of illegal gears and empower } \\
\text { community institutions }\end{array}$ \\
Organizing saving groups & $\begin{array}{l}\text { Encourage communities not to use corals for the } \\
\text { production of lime }\end{array}$ \\
\hline
\end{tabular}


Restore mangroves

Empower women to move away from fishing toward other forms of income generation

Both in Kenya and Mozambique, changes in communities fishing and extractive practices were amongst the most voted. These include banning gears, restoring traditional fishing, discourage the use of corals for lime production. In Mozambique, raising community awareness was overwhelmingly more voted.

A few "innovations" in the form of multi-actor actions were envisioned. In Mozambique these were the creation of a system for resource monitoring and the development of projects for mangrove restoration. These innovations would involve government, communities and specialized organizations. In Kenya, a greater number of innovations were consider. Amongst the most voted ones were the creation of Saving Groups (for BMUs, women groups, youth), carbon sequestration through mangroves plantation, a gear exchange program where government and NGO's would remove illegal gears while at the same time providing other gear and training to fisherfolk.

\section{4. "Seeds" session}

Another methodology was also used to create future scenarios. The technique received relatively less time than the scenario approach described above. The design was inspired by the 'seeds approach' (Bennett et al. 2016). The "seeds approach" utilizes an appreciative inquiry approach [1] focusing on the aspects of the present that are positive (seeds) and could be scaled up to generate a positive future. The approach has been applied in a range of different cases. In this workshop series due to time constrains a limited version was conducted.

To set up the scene, two key ideas were presented in plenary. First participants were introduced to the notion of the Anthropocene and the challenges that this new social-ecological context engenders. Then the three-horizon framework [2] was introduced as a way to think about how existing projects can evolve, connect and scale-up to impact the unsustainable regimes.

From here, using a standard form, participants were asked to describe one "seed" (existing initiative, a project, an idea, a way of thinking) that they knew of and consider important in creating a sustainable and just future. In the next step, in small groups, each participant took the turn to describe the "seed" to other group members, explaining what it was about, who are involved, and were asked to reflect on factors that may "make the seed grow" or restrict it.

Finally, participants were invited to develop a positive story of the future by finding linkages between the seeds. Other "random" seeds were also distributed by convener scientists that represented "disrupting elements", for example "electric trains", "free open internet access".

After each of the storylines were created, each group took turns to present them in plenary using pictures, and role-play.

\subsection{Monitoring and participant observation}

Participant observation methodology was applied in each of the meetings. Break-out groups were audio recorded and notes were taken both about the content and the flow of the conversation. 4 notetakers worked in each workshop. Their first task was to capture the content of the discussions in the break-out groups. Secondly, they captured the way in which conversations unfold. A common framework based on Muro et al. (2008) was used for observation (Table S5).

Table S5. Categories of observation

\begin{tabular}{|l|l|}
\hline - Key learning moments : & $\begin{array}{l}\text { Was there an aha! moment? What led to it? } \\
\text { Was there a particular concept or topic that } \\
\text { was important at that moment? }\end{array}$ \\
\hline - Participant experience (moods, attention): & are people tired? bored? alert? happy? \\
\hline
\end{tabular}




\begin{tabular}{|l|l|}
\hline - Roles of participants: & $\begin{array}{l}\text { are participants playing different roles, for } \\
\text { example, is someone an expert, is someone } \\
\text { rephrasing others and helping bridging? }\end{array}$ \\
\hline - Facilitation & $\begin{array}{l}\text { how are comments being taken? are these } \\
\text { comments being heard by all? }\end{array}$ \\
\hline $\begin{array}{l}\text { - Inclusiveness: are different views being } \\
\text { represented? }\end{array}$ & $\begin{array}{l}\text { are there in-depth discussions and dialogue } \\
\text { happening? }\end{array}$ \\
\hline - Opportunities for in-depth dialogue: & $\begin{array}{l}\text { Are participants openly sharing information } \\
\text { and articulating and exposing their views } \\
\text { and interests? Is everyone being respected? }\end{array}$ \\
\hline - Open communication: & $\begin{array}{l}\text { Are there signs of stretching thinking, } \\
\text { exploring ideas together openly? }\end{array}$ \\
\hline - Unrestrained thinking: & \\
\hline - Egalitarian atmosphere: & $\begin{array}{l}\text { :are people being constrained by power } \\
\text { dynamics? }\end{array}$ \\
\hline - Power dynamics & \\
\hline
\end{tabular}

At the end of each session, notetakers debriefed with another member of the team following responding to the following summary questions:

\begin{tabular}{|l|}
\hline Time/ Session \\
\hline Facilitator \\
\hline Note takers \\
\hline First impressions \\
\hline How creative were people? was it easy to imagine? \\
\hline Were there important learning moments? Aha! moments? \\
\hline Were there interesting/important past stories? \\
\hline How was facilitation? \\
\hline Was everybody speaking / being invited? \\
\hline Were there conflicts? \\
\hline What steps were difficult to people? \\
\hline quietest? loudest? roles of participants? \\
\hline Respectful interactions (From 1-10 scale) \\
\hline Free thinking (From 1-10 scale) \\
\hline Open communication (From 1-10 scale) \\
\hline Imagination (from 1-10 scale) \\
\hline creativity (from 1-10 scale) \\
\hline inclusiveness (from 1-10 scale) \\
\hline
\end{tabular}




\section{Data Analysis}

\subsection{Coding scheme}

Key themes were drawn from Newell 2012.

- Key concept
- Abstract
○ Story
- Defining concept
- Conflictual views
o Key term

- Metaphorical mappings

- Narrative
○ Divergent metaphors
- Discussing assumptions
- Not questioning assumptions
- Intervention
- Narrative strengthens via artefacts

- Dynamics

$\begin{array}{ll}\circ & \text { Imagination } \\ \circ & \text { Role play } \\ \circ & \text { Mood (laughter, tiredness) } \\ \circ & \text { Sharing knowledge } \\ \circ & \text { Imaginative leap } \\ \circ & \text { Idea } \\ \circ & \text { Realization } \\ \circ & \text { Productive dialogue } \\ \circ & \text { Power dynamics }\end{array}$

\subsection{Supplementary results}

\begin{tabular}{|l|l|l|}
\hline & Codes & Quote \\
\hline $\begin{array}{l}\text { Developing a } \\
\text { repertoire }\end{array}$ & $\begin{array}{l}\text { Defining } \\
\text { concept }\end{array}$ & $\begin{array}{l}\text { Concept of "community acceptance" in Kenya had 7 meanings } \\
\text { 1. Accepting/owning projects } \\
\text { 2. Not only yes / educated community } \\
\text { 3. Acceptance to change; to new ideas; to participate; to technology; to } \\
\text { development } \\
\text { 4. Fighting back } \\
\text { 5. Acceptance of change } \\
\text { 6. The mindset - "people willing to listen to what others propose, e.g. } \\
\text { education" }\end{array}$ \\
\hline $\begin{array}{l}\text { Developing a } \\
\text { shared conceptual } \\
\text { repertoire }\end{array}$ & Story & $\begin{array}{l}\text { This quote is taken from a discussion around the notion of "trade-offs" } \\
\text { and "winners and losers" of conservation plans. } \\
\text { "Some people have gained, others no. People benefiting feel good, } \\
\text { "Sthers that don't benefit directly don't.. some say oh a school was } \\
\text { roofed, but what is doing it for me". We know that in our community } \\
\text { those people exist, like in Gazi, they are always against everything, they } \\
\text { are the people that are in the high-rank in terms of economic wellbeing. } \\
\text { Even the cutters are people who have good position in the society.. he } \\
\text { doesn't take kids to that school, of course he will always be against } \\
\text { this.. because he initially had the whole area of } 650 \text { hectars to go and cut } \\
\text { but now 100hectars is set aside.. and this place has good poles for him. }\end{array}$ \\
\hline
\end{tabular}




\begin{tabular}{|c|c|c|}
\hline & & $\begin{array}{l}\text { So you cannot always please everyone, maybe this year they won't be } \\
\text { happy about it and next they will. And so these things we need to } \\
\text { always talk to these people, and we try as much as possible to bring } \\
\text { them on board, to make them feel that we're not losing anything out of } \\
\text { this, yeah?" }\end{array}$ \\
\hline $\begin{array}{l}\text { Developing a } \\
\text { shared conceptual } \\
\text { repertoire }\end{array}$ & $\begin{array}{l}\text { Story; } \\
\text { Metaphor }\end{array}$ & $\begin{array}{l}\text { In discussing the concept of "support" one group discusses: } \\
\text { "There are many different types support. Like with the use of mosquito } \\
\text { nets for fishing. It is very difficult for them because they are very poor } \\
\text { and you cannot only have a rule saying they can't fish. To buy a net with } \\
3 \text { or } 4 \mathrm{~cm} \text { mesh costs. They need support". } \\
\text { Another participant said: } \\
\text { "There is a group of PCE, an association, they are saving money weekly, } \\
\text { and by that they contribute. But with time they also need support. If we } \\
\text { see a person carrying something heavy, we need to come and help to } \\
\text { carry it." }\end{array}$ \\
\hline $\begin{array}{l}\text { Developing a } \\
\text { shared conceptual } \\
\text { repertoire }\end{array}$ & Abstract & $\begin{array}{l}\text { During a conversation about the system diagram. } \\
\text { "If we would like to have support, if we create rules, support will } \\
\text { followed. Here we have two influencers rules and support. But we also } \\
\text { have one that is highly influenced: conservation. Conservation depends } \\
\text { on many aspects: it is necessary to sensitize, to have rules, to have } \\
\text { support, to have alternative, it does not depend on market." }\end{array}$ \\
\hline $\begin{array}{l}\text { Developing a } \\
\text { shared conceptual } \\
\text { repertoire } \\
\text { Dynamics }\end{array}$ & $\begin{array}{l}\text { Abstract; } \\
\text { Power } \\
\text { dynamics; } \\
\text { Not } \\
\text { questioned } \\
\text { assumptions }\end{array}$ & $\begin{array}{l}\text { Participants discuss the concept of "collaboration", a representative of } \\
\text { NGO states a "micro-narrative" of "community organizations without } \\
\text { government or NGO will not be able to do any project" } \\
\text { The community group seeks to explain what they mean by } \\
\text { "collaboration": } \\
\text { Community representative: we're here to find out is how to reduce } \\
\text { poverty through ecosystems. Ok, so let's create a project to reduce } \\
\text { poverty. How are we going to do this? First we need to create a group? } \\
\text { NGO: group? what do you mean } \\
\text { Community representative: for example, one group to conserve the } \\
\text { ecosystems. The CCP (community management group) for instance.. } \\
\text { Community representative: this CCP cannot work if there is no } \\
\text { collaboration between members, but it can also not work without } \\
\text { observing laws, and also if there is no support, technical and financial.. } \\
\text { So here we highlighted collaboration as key. Because if there is } \\
\text { confusion between CCP members, as in the case that we were talking.. } \\
\text { if they don't observe laws, then the support might go away } \\
\text { NGO representative: yes, that's what I mean, collaboration is not only } \\
\text { about the CCP. Because the CCP without government or NGO will } \\
\text { not be able to do any project." }\end{array}$ \\
\hline $\begin{array}{l}\text { Developing a } \\
\text { shared conceptual } \\
\text { repertoire } \\
\text { Narrative }\end{array}$ & $\begin{array}{l}\text { Abstract; } \\
\text { Narrative } \\
\text { strengthened } \\
\text { via artefacts }\end{array}$ & $\begin{array}{l}\text { "So we have here a map. If there is good governance (pointing at } \\
\text { laws/rules), good laws and good rules that relate to all activities, or } \\
\text { better, between all actors there is collaboration (pointing at } \\
\text { collaboration concept). Just to make it more clear.. what is it going to } \\
\text { happen at sea? today people will go for petroleum, fisherfolk have been } \\
\text { there for long, and in a while we will be the ones loosing those areas.. } \\
\text { our fishing resource will probably be reduced and we will have no place } \\
\text { to fish.. but having good collaboration, we will not feel this directly. } \\
\text { There needs to have a very strong support in the form of projects.. as }\end{array}$ \\
\hline
\end{tabular}




\begin{tabular}{|c|c|c|}
\hline & & $\begin{array}{l}\text { neighbors. Fisherman is there, the other is there extracting salt, the } \\
\text { other is petroleum.. and all of that happening in the area of the } \\
\text { fisherfolk.. and so the fisherfolk should have access to education and } \\
\text { capacity building." }\end{array}$ \\
\hline Narratives & $\begin{array}{l}\text { Not } \\
\text { questioning } \\
\text { assumptions }\end{array}$ & $\begin{array}{l}\text { Micro-narratives are expressed and their assumptions are not } \\
\text { questioned. For instance, } \\
\text { Participant says "For poverty level, you know we depend on donor } \\
\text { funding, I don't think low security will be good. In terms of ecosystem } \\
\text { health it will be good if there is a project they accept in the community. } \\
\text { Conservation is a requirement, so our coastal ecosystems will be there." } \\
\text { The assumption of dependence of poverty alleviation on donor funding } \\
\text { has not been questioned. Nor the assumption of positive impact of } \\
\text { conservation on community. }\end{array}$ \\
\hline $\begin{array}{l}\text { Breaking away } \\
\text { from narratives: } \\
\text { Transformative } \\
\text { ideas }\end{array}$ & $\begin{array}{l}\text { Narrative } \\
\text { strengthened } \\
\text { via artefacts }\end{array}$ & $\begin{array}{l}\text { During the pre-workshop interview the participant emphasized the need } \\
\text { for collaboration across actors to better tackle poverty. } \\
\text { During the final plenary of workshop 1, while all participants were } \\
\text { convened in plenary, the participant utilized the visual representations } \\
\text { of the systems to resonate the view on collaborations: } \\
\text { Participant: "The biggest lesson here to put into practice the synergies, } \\
\text { because they exist, but what happens is that we work in isolation and } \\
\text { there is no way that we will find any solution if each one wants to pull } \\
\text { the fish to his fire. These systems show clearly that one isolated } \\
\text { institution is very unlikely to find a solution. The most important is to } \\
\text { find the common denominator to solve the equation in the sense of } \\
\text { encompass the various perspectives." }\end{array}$ \\
\hline
\end{tabular}

\subsection{Knowledge co-creation illustration}

An artistic representation was developed to illustrate the movement of knowledge co-creation taking inspiration of the work of Newell (2012) (Figure S14). Newell (2012) describes Figure S14 as "dependence of conceptual overlap on level of abstraction. The horizontal axis represents the range of concepts that make up a person's conceptual repertoire. The vertical axis represents the level of abstraction of the concepts needed to reason and communicate about a given situation. The curved areas labelled RA and RB represent the extent of the conceptual repertoires of Persons A and B, respectively. The horizontal lines labelled S1, S2 and S3 represent situations at three different levels of abstraction".

Based on insights from our process we propose that knowledge co-creation can build shared understandings and social-ecological narratives from less abstract forms of communication.

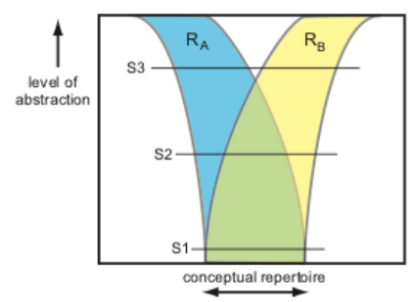

Figure S14. Conceptual framework utilized to develop the artistic representation in the manuscript. Adapted from Newel (2012). 


\section{References}

Bennett EM, Solan M, Biggs R, McPhearson T, Norström AV, Olsson P, Pereira L, Peterson GD, Raudsepp-hearne C, Biermann F, et al.: Bright spots: seeds of a good Anthropocene. Frontiers in Ecology and the Environment 2016, 14:441-448.

Cooperrider DL, Peter FS Jr, Whitney D, Yaeger TF: Appreciative inquiry: Rethinking human organization toward a positive theory of change. Team Performance Management 2000, 6:140140.

Muro M, Jeffrey P: A critical review of the theory and application of social learning in participatory natural resource management processes [Internet]. Journal of Environmental Planning and Management 2008, 51:325-344.

Newell, B., C. L. Crumley, N. Hassan, E. F Lambin, C. Pahl-wostl, A. Underdal, and R. Wasson. 2005a. A Conceptual Template for Integrative Human-Environment Research. Global Environmental Change 15 (4): 299-307. doi:10.1016/j.gloenvcha.2005.06.003.

Sharpe B, Hodgson A, Leicester G, Lyon A, Fazey I: Three horizons: a pathways practice for transformation. E\&S 2016, 21:art47.

SPACES. 2017. "Sustainable Poverty Alleviation From Coastal Ecosystem Services Project Publications." SPACES Project Website www.espa-spaces.org. Accessed August 82017. 